\title{
COVID-19, Mudanças em Práticas Educacionais e a Percepção de Estresse por Docentes do Ensino Superior no Brasil
}

\author{
Title: COVID-19, Changes in Educational Practices and the Perception of Stress by Higher \\ Education Teachers in Brazil
}

\author{
Renata Mendes de Araujo \\ Universidade Presbiteriana Mackenzie \\ Programa de Pós-Graduação em \\ Sistemas de Informação - EACH/USP \\ renata.araujo@mackenzie.br
}

\section{Maria Amélia Eliseo}

Universidade Presbiteriana Mackenzie mariaamelia.eliseo@mackenzie.br

\author{
Cibelle A. de la Higuera Amato \\ Universidade Presbiteriana Mackenzie \\ Programa de Pós-Graduação em \\ Distúrbios do Desenvolvimento \\ cibelle.amato@mackenzie.br
}

\author{
Ismar Frango Silveira \\ Universidade Presbiteriana Mackenzie \\ Programa de Pós-Graduação Em \\ Engenharia Elétrica e Computação \\ ismar.frango@mackenzie.br
}

\author{
Valéria Farinazzo Martins \\ Universidade Presbiteriana Mackenzie \\ Programa de Pós-Graduação em \\ Distúrbios do Desenvolvimento \\ valeria.farinazzo@mackenzie.br
}

\begin{abstract}
Resumo
A pandemia decorrente da COVID-19 trouxe mudanças profundas para toda a sociedade, seja no seu contexto social ou profissional. Escolas e Universidades no Brasil e no Mundo fecharam com a intenção de frear a contaminação da COVID-19 e muitos professores se viram obrigados, num curto periodo de tempo, a reinventar suas aulas presenciais em uma modalidade não presencial, mediadas pela tecnologia. No entanto, nem todos os professores, que no seu cotidiano já possuem uma sobrecarga de trabalho, estavam preparados para esta mudança tão repentina. Muitos se viram obrigados a adquirir novos conhecimentos em relação ao uso das tecnologias para integrá-las nas suas atividades pedagógicas, aumentando ainda mais esta sobrecarga. Este cenário de trabalho excessivo pode leválo ao estresse, favorecendo quadros de angústia, além de ansiedade e depressão devido às incertezas decorrentes da pandemia, à busca por aquisição de conhecimento e à intensificação do fluxo de informação. Neste contexto, este artigo mostra os resultados provenientes de uma pesquisa realizada com 394 professores universitários, que estejam ou tenham estado em isolamento social imposto pelo COVID-19 exercendo atividade docente. O objetivo foi compreender os fatores de estresse relacionados às mudanças urgentes e em caráter de contingência nas práticas de ensino na educação superior decorrentes da pandemia, no Brasil. Os resultados mostram que a percepção de estresse é real entre os docentes do ensino superior no Brasil que se mantiveram em atividade de ensino remoto durante o isolamento social decorrente da pandemia; há predominância de estresse nas professoras em relação aos professores; professores das áreas de Ciências Jurídicas e da Saúde parecem perceber mais o estresse; aqueles que se declararam com um nível de habilidade no uso de tecnologia mais baixo são os que mais sentiram as variáveis de estresse durante a pandemia.
\end{abstract}

Palavras-Chave: Pandemia; COVID-19; Educação a Distância; Ensino Superior; Estresse; Universidades

\begin{abstract}
The pandemic resulting from COVID-19 brought about profound changes for the whole of society, whether in its social or professional context. Schools and Universities in Brazil and in the World closed with the intention to prevent the spread of COVID-19 and many teachers were forced, in a short period of time, to reinvent their face-to-face classes in a non-face-to-face mode mediated by technology. However, not all teachers, who in their daily lives already have an overload of work, were prepared for this sudden change. Many were forced to acquire new knowledge Cite as: Araujo, R. M.; Amato, C. A. H.; Martins, V. F.; Eliseo, M. A. \& Silveira, I. F. (2020). COVID-19, Changes in Educational Practices and the Perception of Stress by Higher Education Teachers in Brazil (COVID-19, Mudanças em Práticas Educacionais e a Percepção de Estresse por Docentes do Ensino Superior no Brasil). Brazilian Journal of Computers in Education (Revista Brasileira de Informática na Educação - RBIE), 28, 864-891. DOI: 10.5753/RBIE.2020.28.0.864
\end{abstract}


regarding the use of technologies to integrate them in their pedagogical activities, further increasing this burden. This scenario of overwork can lead to stress, favoring distress, in addition to anxiety and depression due to the uncertainties resulting from the pandemic, the search for knowledge acquisition and the intensification of the information flow. In this context, this article shows the results of a research carried out with 394 university professors, who are or have been in social isolation imposed by COVID-19 exercising teaching activity. The goal was to understand the stress factors related to urgent and contingency changes in teaching practices in higher education resulting from the pandemic in Brazil. The results show that the perception of stress is real among higher education teachers in Brazil who remained in remote education activity during the social isolation resulting from the pandemic; there is a predominance of stress in teachers in relation to teachers; professors in the areas of Legal Sciences and Health seem to perceive stress more; those who declared themselves to have a lower skill level in the use of technology are those who most felt the stress variables during pandemic.

Keywords: Pandemics, COVID -19; e-Learning; Higher education; Stress; University

\section{Introdução}

Um dos grandes impactos da pandemia decorrente da COVID-19 tem sido uma profunda mudança na forma de atuar e interagir profissional e socialmente por meio de tecnologias. Tecnologias de interação online são velhas conhecidas desta geração, mas nunca foram tão utilizadas, criticadas e aperfeiçoadas como nestes tempos e, sobretudo, necessárias para a continuidade de negócios e das atividades de ensino e aprendizagem.

As escolas e as universidades brasileiras se fecharam como medida de conter o avanço da pandemia e nos vimos - docentes, alunos e profissionais da administração - empenhados em dar continuidade às nossas ações de ensinar aprender por intermédio do que se pode chamar de vários nomes: Ensino a Distância, Ensino Online, Ensino Híbrido, Atividade Escolar Remota, entre outras denominações. Os docentes, em particular, agentes fundamentais do processo de ensino, se viram abrupta e urgentemente responsáveis por alterar significativamente suas práticas pedagógicas, não sem um universo de indagações:

"Enquanto professores, temos sentimentos ambíguos em relação a essa situação. Por um lado, não nos parece razoável cruzar os braços e suspender por completo as aulas por vários meses. Por outro, nos causa apreensão migrar abruptamente a educação presencial de nosso país para modalidades não presenciais, pois há saberes pedagógicos típicos dessas outras abordagens que não são de domínio de todos os professores. Manter as aulas em que condições? Como os professores, que não têm formação ou experiência em modalidades não presenciais, irão atuar? Com que conteúdo? Como será a mediação docente? Por meio de que sistemas computacionais? Teremos suporte? Dará tempo para fazer um novo desenho didático para a disciplina? E as questões trabalhistas? Os alunos, que são de cursos presenciais, conseguirão se adaptar à interação não presencial? Como os alunos que não possuem adequada infraestrutura em suas casas participarão dessas aulas mediadas pelas tecnologias? Esses são alguns questionamentos e desafios que vários de nós precisamos enfrentar neste momento." (Araujo \& Pimentel, 2020)

A migração contingencial dos cursos presenciais para a modalidade não presencial se viu cercada de tensões, não só na necessidade de reinventar suas práticas de trabalho, como na revisão de suas relações entre os principais atores do sistema de educacional: governo, instituições, gestores, colegas e alunos, e também nas rotinas particular e familiar dos docentes. É conhecido que o professor se depara com uma quantidade de trabalhos bastante expressiva, que acabam por sobrecarregá-lo, sendo, assim, uma das profissões mais suscetíveis ao estresse e à síndrome de Burnout. Por estresse, entende-se, no contexto deste trabalho, todo tipo de consequência sistêmica 
acarretado por um conjunto de estímulos que levam um indivíduo a um estado particular de excitação emocional (Plessis, 2019) (Prado, 2016). Já a síndrome de Burnout, caracterizada como um fenômeno ocupacional e registrada na Classificação Internacional de Doenças sob o código ICD-11, refere-se a um estado crônico de estresse relacionado ao trabalho. Tal síndrome encontrase relacionada com os sentimentos de exaustão e exaurimento de energia, bem como a adoção de posturas distantes, negativas ou céticas em relação ao trabalho. Estes fatores, por sua vez, frequentemente acarretam uma queda na produtividade do indivíduo (Faria \& Gallo-Pena, 2009) (Carlotto \& Palazzo, 2006).

As alterações sem precedentes nas práticas educacionais para modelos online e futuramente híbridos em caráter emergencial abrem espaço para questões relacionadas à saúde mental que requerem análise (Araújo et al., 2020; Sahu, 2020), principalmente relacionadas à geração de estresse, favorecendo quadros de angústia. Ansiedade e depressão, exacerbadas por incertezas, uma busca feroz por aquisição de conhecimento e a intensificação do fluxo de informação, devem aumentar largamente neste processo, trazendo consequências fisiológicas negativas, como estresse.

Neste artigo apresentamos os resultados de um levantamento de informações com docentes do ensino superior no Brasil, buscando compreender os fatores de estresse relacionados a estas mudanças urgentes e em caráter de contingência nas práticas de ensino decorrentes da pandemia. Realizamos um levantamento de dados por meio de questionário online, respondido por 456 professores universitários que estejam ou tenham estado em isolamento social imposto pelo COVID 19 exercendo atividade docente, escolhidos por conveniência. Os dados coletados foram submetidos à análise qualitativa e quantitativa para nos ajudar a compreender: a) a ocorrência ou não de sinais de estresse entre os docentes de ensino superior durante o período de isolamento e migração de aulas remotas; e b) as relações entre os níveis de sinais de estresse e outras variáveis relacionadas ao perfil pessoal, atuação docente, contexto de isolamento, experiência com ferramentas e métodos para ensino online e relações de trabalho. Os dados resultantes da pesquisa apontam para a existência de fatores de estresse entre os professores que se envolveram em atividades remotas durante a pandemia do COVID-19, com destaque para gênero, área de atuação e habilidades no uso de tecnologia.

Este artigo está organizado da seguinte forma: na seção 2 apresentamos os fundamentos conceituais do trabalho, em particular os conceitos de estresse e aulas remotas; na seção 3 discutimos trabalhos similares encontrados na literatura recente sobre os impactos da pandemia nas atividades de trabalho docente; na seção 4 detalhamos o método de levantamento utilizado na pesquisa, descrevendo o instrumento de levantamento de dados, bem como os procedimentos de coleta e análise dos dados; a seção 5 descreve as análises a partir dos dados coletados e sua discussão; a seção 6 conclui o artigo apontando oportunidades de trabalhos futuros.

\section{Fundamentação Teórica}

\subsection{Estresse}

De acordo com Hindle (1998), o estresse é caracterizado por um conjunto de reações do organismo geradas por qualquer agressão de cunho físico, psíquico ou até infeccioso. O estresse, quando positivo, está ligado ao aumento de produtividade e criatividade. Porém, quando carrega sua carga negativa, dá origem a consequências como cansaço, irritabilidade, falta de concentração, depressão, queda de resistência imunológica, entre outros fatores (Faria \& Gallo-Pena, 2009). Isso acontece quando é exigido do organismo mais do que sua capacidade normal, afetando várias dimensões das relações, seja no nível familiar, social e de trabalho (quando o ambiente de trabalho gera estímulos que precisam ser respondidos pelo trabalhador) 
Para Prado (2016), o estresse é uma doença crônica recorrente, que causa diminuição da capacidade de trabalho e/ou desgaste do organismo humano. Destaca como principais agentes estressores os fatores organizacionais e ambientais e reforça que o diagnóstico é essencialmente clínico considerando os sintomas que podem ser comportamentais, físicos e psicológicos. Complementa que o enfoque das investigações científicas deve ser na tentativa de ampliar as relações entre o estresse ocupacional e o adoecimento e sofrimento que acarreta.

O estresse está relacionado a maneira como o indivíduo percebe e avalia os eventos como estressores e como responde aos mesmos (Genuíno et al. 2009). De acordo com Lipp (2002), o estresse está dividido em quatro fases inter-relacionadas e incrementais:

- Alerta: a pessoa entra em contato com o agente agressor e seu metabolismo é aumentado. Pode ser considerado positivo, mas traz consequências como dificuldade para dormir, grande produtividade e criatividade no âmbito profissional e grande irritabilidade devido à tensão física e mental enfrentadas.

- Resistência: o organismo, exausto, dá sintomas de cansaço - diminuição da produtividade e criatividade, memória afetada, dores de cabeça frequentes, gripes e viroses constantes.

- Quase-Exaustão: o limite não é mais gerenciável, afetando o indivíduo com insônia, perda drástica de produtividade e criatividade, desgaste.

- Exaustão: o indivíduo muitas vezes já não pode trabalhar e aparecem doenças como a hipertensão, a diabetes e a síndrome do pânico.

Os agentes causadores do estresse podem ser internos ou externos. Em relação aos internos estão: relações de perdas, dificuldades financeiras, excesso de trabalho, preconceitos, responsabilidades excessivas. Em relação aos agentes externos estão: mudança de emprego, perda de um ente querido, sofrer um sequestro, etc (Sadir, Bignotto \& Lipp, 2010).

Baião e Cunha (2013) realizaram uma revisão de literatura que identificou o estresse como uma das doenças e disfunções mais comuns entre docentes investigados. No estudo os autores destacam que o estresse é uma condição potencial de afastamento do docente de seu trabalho por provocar incapacidades física e psicológica. Os autores complementam que fatores relacionados ao estilo de vida como sedentarismo e pouco lazer são facilitadores do adoecimento. Estes são fatores muito presentes no contexto atual de distanciamento social imposto pela pandemia do COVID-19.

Referindo-se à profissão docente, o professor já se depara com uma quantidade de trabalhos bastante expressiva, que acabam por sobrecarregá-lo. Além de ministrar aulas, o professor incorre em trabalhos administrativos, planejamento de suas atividades, preocupação com a aquisição de novos conhecimentos, orientação a estudantes, atividades extra-escolares, como participação em reuniões de coordenação, seminários, preenchimento de relatórios periódicos. No entanto, a ele não é dada a oportunidade, muitas vezes, de participar das decisões institucionais, de reestruturações curriculares, de repensar a engrenagem entre disciplinas (Carlotto \& Palazzo, 2006; Alves \& Pereira Neto, 2019). Alguns autores relacionam as mudanças no contexto de aprendizagem com a inclusão das tecnologias e as estratégias de adaptação adotadas pelos professores como razões para a ocorrência do estresse crônico, conhecido como síndrome de Burnout (Lipp, 2004).

Independentemente do cenário de pandemia, alguns trabalhos já reportavam o estresse docente na prática da educação à distância ou online. Plessis (2019) analisou 305 docentes de ensino a distância em uma universidade sul africana, em sua maioria mulheres $(64,3 \%)$, idade média de 45 anos, em número equilibrado de mestres e doutores, e empregados há mais de 10 anos $(62 \%)$. a pesquisa identificou que os fatores principais de estresse reportados pelos docentes estão relacionados a questões organizacionais e específicas do trabalho acadêmico (carga 
excessiva de trabalho, demandas crescentes de estudantes, deveres administrativos, pressões por publicações). Além disso, os respondentes percebem que a ausência de recursos e suporte organizacional (gestão e colegas de trabalho) contribuem para seu estresse.

Poalses e Bezuidenhout (2018) realizaram um estudo com 294 acadêmicos, também em uma universidade sul africana, onde somente cursos online são oferecidos, para compreender os fatores de estresse relacionados ao trabalho neste contexto. Os resultados principais desta pesquisa expõem a percepção dos respondentes de experimentarem pressões por prazos, sobrecarga de trabalho e aumento nos níveis de estresse, podendo levar a longo prazo a doenças ou à redução de comprometimento com o trabalho. Os respondentes demonstraram também um alto nível de insegurança de emprego, a percepção de terem pouco controle ou autonomia sobre diversos aspectos de seu trabalho e não por não possuírem influência sobre suas metas de desempenho, o que leva também à diminuição do comprometimento e estresse. A pesquisa menciona também as questões associadas à prática docente online relacionadas à tecnofobia (fuga de novas soluções tecnológicas), à sobreidentificação tecnológica (a tecnologia consome mais tempo do que o desejado) e ao technostress (ansiedade e pressão mental devido à exposição e envolvimentos excessivos à tecnologia).

Pelo exposto, fica evidente pela própria natureza de seu trabalho como também no contexto que exerce suas funções, que o professor está suscetível a muitos fatores estressores, que podem levá-lo à síndrome de Burnout (Carlotto \& Palazzo, 2006). A síndrome de Burnout, segundo (Maslach \& Jackon, 1981; Leiter \& Maslach, 2017), é originada na perspectiva social-psicológica. Ela possui três dimensões relacionadas, mas independentes:

- exaustão emocional: falta de energia e entusiasmo, esgotamento, sentimento de frustração e tensão nos trabalhadores;

- despersonalização: dificuldades nas relações interpessoais no cotidiano de trabalho; e

- diminuição da satisfação pessoal no trabalho: auto-avaliação negativa, tornando-se infeliz e insatisfeito com seu desempenho profissional.

Entre professores, a síndrome de Burnout tem interferido na obtenção dos objetivos pedagógicos, levando a um processo de alienação, desumanização e apatia, trazendo problemas de saúde e até a intenção de abandonar a profissão (Cordeiro et al., 2003; Guglielmi \& Tatrow, 1998).

Nos últimos 15 anos houve crescente deterioração da carreira docente com precarização das relações interpessoais no trabalho e desvalorização profissional. O estresse causado em muitos professores já é considerado como fator adverso na saúde global. (Weber et al., 2015). Há o reconhecimento internacional do estresse como uma enfermidade profissional muito relacionada ao ambiente educacional. Estudos realizados em outros países destacam a deterioração da saúde física e mental dos docentes (Martins, 2007; Prado, 2016).

\subsection{Aulas Remotas}

Embora a Educação a distância (EaD) tenha se consolidado a partir de sua integração com recursos digitais, sua prática ocorre desde o início da era Cristã, quando São Paulo usou as tecnologias de escrita da época e dos meios de transporte para sua pregação tanto presencial quanto assíncrona (Peters, 2004). Nos anos 70, havia algumas alternativas para que os estudantes tivessem a possibilidade de realizar um curso longe de seu professor. $O$ chamado estudo por correspondência mantinha instrutores que enviavam e recebiam as lições impressas pelo correio. Também havia a opção de entrega de material didático pelo rádio e pela TV (Peters, 2004; Moore \& Diehl, 2019). Estas práticas de ensino fora da sala de aula eram vistas com menosprezo pelas instituições de ensino, por isso não havia uma preocupação com pesquisas acadêmicas sobre métodos de ensino a distância (Moore \& Diehl, 2019). 
Neste contexto, o termo "Educação a distância" foi proposto, no início dos anos 70, para estabelecer a identidade de outra forma de ensino e aprendizagem longe da sala de aula. Moore (1972) definiu educação a distância como "a família de métodos instrucionais nos quais os comportamentos de ensino são executados além dos comportamentos de aprendizagem... para que a comunicação entre aluno e professor seja facilitada por meio impresso, eletrônico, mecânico ou outro dispositivo". Moore (1972) identifica, a partir de uma análise empírica de uma seleção de programas de $\mathrm{EaD}$, três conjuntos de fatores críticos: a estrutura do programa de ensino, as interações ou diálogo entre estudantes e professores e a autonomia dos estudantes que devem decidir sobre o que aprender, como aprender, quanto aprender, decisões estas, num ambiente presencial, normalmente decidida pelo professor. Dentre as definições atuais, EaD é uma forma de ensino e aprendizagem onde alunos e professores estão separados, física ou temporalmente e comunicam e gerenciam diálogos por meio das tecnologias de informação e comunicação (TICs) (Moore \& Diehl, 2019; Brasil, 2018).

Costa (2007) destaca que a EaD, ao definir diferentes espaços de atuação entre professores e alunos, deve impor a mediação do processo pedagógico realizada por uma equipe constituída de tutores presenciais e de tutores a distância. Esta mediação usufrui das TICs que devem ser acessíveis aos estudantes. Ainda para garantir a qualidade do processo é fundamental a existência de estruturas físicas descentralizadas de apoio ao estudante, genericamente designadas por "pólos de apoio presencial ao estudante", oferecendo apoio administrativo e acadêmico, laboratórios de computadores em rede, com acesso à Internet, salas para encontros presenciais e laboratórios para realização de tutorias experimentais, espaços pedagógicos para os estágios supervisionados e outras estratégias. Este modelo de ensino e aprendizagem deve ser estruturado considerando o aluno como centro do processo pedagógico.

Os ambientes virtuais de ensino e aprendizagem (AVEAs) favorecem a mediação entre professores e alunos, não só no $\mathrm{EaD}$, como também nas aulas presenciais, em sala de aula. Tratase de um sistema computacional que utiliza dos recursos da Internet e oferece suporte ao professor na criação e condução de cursos, que inclui a inserção e gerenciamento de atividades pedagógicas e disponibilização de materiais didáticos. Assim, o estudante possui um ambiente para realizar tarefas, discutir temas propostos, consultar materiais disponibilizados além de interagir com os colegas e professores (Lazzarotto et al., 2011) de forma síncrona ou assíncrona. Com este suporte dos AVEAs, o processo de ensino aprendizagem expande a escolha do que, quando, onde e como se aprende, evidenciando o protagonismo estudantil, oferecendo suporte aos diferentes estilos de aprendizagem.

Com uma abordagem diferente da $\mathrm{EaD}$ e se aproveitando dos AVEAs, o aprendizado online supera as restrições de espaço e tempo, propondo metodologias pedagógicas mediadas pela tecnologia. O conceito de aprendizado online está relacionado ao e-learning que se aproveita dos recursos oferecidos pela Internet para difusão e conexão de conteúdo, facilitando a colaboração entre os estudantes e tornando o aprendizado focado no aluno (Aparicio \& Bacao, 2013).

Combinando a aprendizagem online com a aprendizagem tradicional presencial, surge o ensino híbrido que tem sido uma opção promissora para tornar o processo ensino aprendizagem mais atraente e motivador (Luca, 2006). No ensino híbrido, parte do conteúdo didático é transmitido de forma online de tal modo que o aluno possa gerenciar seu tempo, local e ritmo de seu aprendizado, sem deixar de lado o respaldo dos professores na condução do ensino presencial (Sarmento, Gomes \& Moreira, 2018).

Outra possibilidade de mediação pedagógica oferecida pelas TICs são as aulas virtuais síncronas por meio de webconferência, que oferecem múltiplas possibilidades de interação. Possibilita o compartilhamento de arquivos, aplicativos, telas do computador etc. Também possuem recursos comuns às salas de aula, como quadro branco e organização de grupos, ferramentas que auxiliam na condução de aulas e atividades colaborativas (Dotta et al., 2014). 
Nesta modalidade, professores ou tutores e alunos encontram-se fisicamente separados, mas de forma síncrona. Esta sincronicidade necessita de estratégias diferenciadas para criar uma sinergia entre professores e alunos na tarefa de construção do conhecimento. Cabe ao professor gerenciar a comunicação utilizando-se dos recursos oferecidos pela webconferência (salas de bate-papo, compartilhamento de arquivos, apresentação de slides ou vídeos, etc.) para tornar a aula mais atrativa.

Com a pandemia decorrente da COVID 19, muitas instituições de ensino foram obrigadas a encontrar alternativas, quase sempre apoiadas por tecnologias digitais, às aulas presenciais - ainda que a emergência que se impôs se contrapusesse a um certo conservadorismo de muitas instituições quanto à utilização de tecnologias digitais, como bem apontado por Weller (2020). Algumas destas instituições já vinham neste processo de transformação propondo o ensino híbrido em várias disciplinas. Mas, com a aceleração deste processo, muitos professores tiveram que se adaptar, repentinamente, a um ensino mediado pelas TICs, seja de forma síncrona por meio dos recursos das webconferências, seja de forma assíncrona utilizando o apoio dos AVEAs, ou por uma mescla de ambas. Por outro lado, autores como Lederman (2020) mostram um rechaço por parte do corpo discente, apontando uma perda de qualidade em relação à adoção de aulas remotas e reclamando, no caso das instituições pagas, o retorno de suas mensalidades ou protestando por descontos.

Kuklinsi e Cobo (2020) exibem um arrazoado de novos cenários impostos pela urgência de adoção de soluções remotas, em um contexto por eles denominado DRE (Docência Remota de Emergência), enquanto Hodges et al. (2020) nomeiam o atual contexto de Ensino Remoto de Emergência (ERE). Esses últimos ressaltam o viés de improvisação e de transferência quase imediata das experiências das aulas presenciais ao contexto de aulas remotas.

De acordo com Kuklinsi e Cobo (2020), provavelmente um número considerável de instituições irá retomar suas práticas habituais assim que as nações conseguirem, por algum meio, controlar a pandemia da COVID-19. Entretanto, os mesmos autores defendem que há a possibilidade de que as lições aprendidas neste período se reflitam nas práticas futuras de algumas instituições, em quatro possíveis cenários:

- Cenário 1 (Ensino Remoto Não-Adaptado): Sem muitas mudanças metodológicas, com aulas expositivas longas por videoconferência e pouca interatividade. Este cenário se caracteriza por um esforço voluntário dos docentes em relação aos esforços para apropriação dos saberes tecnológicos necessários ao exercício da docência. Não se percebe uma alteração significativa nos processos avaliativos; a mudança mais perceptível nas metas instrucionais se relaciona majoritariamente a uma maior flexibilidade, tolerância e empatia, tanto da instituição em relação aos docentes e estudantes, quanto do corpo docente em relação ao corpo discente.

- Cenário 2 (Ensino Remoto Adaptado): Em relação ao cenário anterior, destacamse: maior ajuste e curadoria dos conteúdos; dinâmicas distintas de avaliação incluindo avaliação por pares e autoavaliação; substituição de longas sessões de videoconferência por sessões mais curtas e direcionadas, entremeadas por momentos de mentoria individual e apresentações/entrega de trabalhos individuais.

- Cenário 3 (Ensino Remoto Aspiracional): Este cenário diferencia-se do anterior por contar com sequências de aprendizagem bem definidas, baseadas em resolução de problemas, facilitando a colaboração entre docentes em direção ao que os autores denominam de "cátedras integradoras". Neste cenário, o docente é visto como um projetista de experiências de aprendizagem, mesclando sessões curtas de videoconferência para aulas expositivas e sessões mais longas para trabalho síncrono em equipe, proporcionando uma melhor integração dos momentos síncronos com assíncronos. Em termos de avaliação, este cenário prevê a aplicação de estratégias de 
avaliação em um contexto transversal, com a adoção de práticas distintas, que incluem gamificação da avaliação, por exemplo.

- Cenário 4 (Ensino Híbrido Aspiracional): Este cenário prevê a integração de experiências remotas de sucesso no ensino presencial, convertendo a remotos todos os processos em que a presencialidade não agregue valor significativo, reduzindo assim as aulas teóricas presenciais com baixo nível de interatividade. Em termos de organização curricular, a presença maciça de cátedras integradoras; já no que se refere à avaliação, traz-se uma valorização da construção de portfólios profissionais e certificações parciais.

\section{Trabalhos Relacionados}

Foram encontrados, na literatura, alguns trabalhos relacionados a esta pesquisa, no que se refere às relações entre estresse e atividade docente durante o período de isolamento social em decorrência da pandemia.

Especificamente sobre as relações entre estresse e prática docente online no contexto da pandemia, um projeto realizado pela Fundação Carlos Chagas (2020), desenvolveu uma pesquisa em relação à educação escolar em tempos de pandemia, com mais de 14 mil respondentes professores e professoras de todas as 27 Unidades da Federação Brasileiras. Nesta pesquisa, com 24 questões fechadas e duas abertas, foram tratados temas relacionados ao aumento das atividades docentes, estratégias educacionais utilizadas, organização do tempo com os alunos, aprendizagem, ansiedade/depressão, retorno às aulas presenciais, relação escola-família, apoio da escola, entre outros. Nesta pesquisa, é reportado pelos professores uma mudança e aumento das atividades docentes, com maior percepção de mudança nas atividades que envolvem novas formas de interação com alunos por meio de tecnologias digitais. A questão do estresse do docente, no entanto, não é abordada na pesquisa.

Odriozola-González et al. (2020) realizaram um levantamento sobre sintomas de depressão, ansiedade e estresse na Universidade de Valladolid, Espanha, durante as primeiras semanas de confinamento. $\mathrm{O}$ estudo abrangeu um questionário direcionado à toda a comunidade universitária para levantamento de aspectos relacionados à depressão, à ansiedade e ao estresse (usando a escala DASS-21) e o impacto emocional da pandemia nestes segmentos (usando a escala IES). Foram coletados dados de 2.500 respondentes $(76,8 \%$ estudantes, $13,4 \%$ docentes - 339 respondentes e $9,8 \%$ pessoal administrativo). O estudo identificou níveis significativamente mais altos de estresse nos alunos do que no corpo profissional na universidade. Especificamente em relação ao corpo docente, os docentes das áreas de Artes e Humanidades apresentaram resultados estatísticos significativamente mais altos nas escalas de depressão, ansiedade e estresse, seguidos dos docentes da área de Saúde, Ciências e Ciências Sociais e Direito e, por fim, os docentes das áreas de Engenharia e Arquitetura.

Huang e Zhao (2020) analisaram os dados de um levantamento nacional realizado na China para avaliar o impacto da pandemia na saúde mental dos trabalhadores em geral. Dos 7.236 respondentes do questionário, 1.404 era professores (universitários, ensino médio e ensino básico). Os aspectos principais levantados na pesquisa foram sintomas desordem de ansiedade generalizada, depressão e qualidade do sono. Em relação especificamente aos docentes, 35,1\% apresentaram sintomas de ansiedade, $21 \%$ de depressão e 14,3 relataram problemas na qualidade do sono. Comparativamente a outras categorias profissionais (profissionais da saúde, trabalhadores em empresas e outros), o percentual de respondentes docentes com sintomas de ansiedade e depressão foi proporcional aos demais profissionais, incluindo os da saúde, à exceção dos sintomas de qualidade de sono que, para os professores, foi menor. 
Pather et al. (2020) realizaram um estudo qualitativo com 18 docentes da disciplina de anatomia de 10 universidades na Austrália e Nova Zelândia, que tiveram que alterar emergencialmente suas práticas de ensino para atividades remotas durante os primeiros meses de isolamento social imposto na região. Os entrevistados reportaram uma drástica mudança em seu modelo de trabalhar, apesar de permanecerem focados nas questões pedagógicas, as expectativas e habilidades para desenvolvê-las haviam mudado, principalmente relacionadas à capacitação e uso adequado de tecnologias para este fim. Os respondentes também reportaram preocupações com a sustentabilidade de seus empregos, devido a cortes orçamentários e o grande aumento da carga de trabalho para preparação de material educacional, suportada principalmente pela contrapartida do sentimento de satisfação com o aprendizado dos alunos.

A Tabela 1 resume os principais aspectos dos trabalhos relacionados encontrados e sua comparação com a presente pesquisa.

Tabela 1: Aspectos principais dos trabalhos estudados e comparação com a presente pesquisa

\begin{tabular}{|c|c|c|c|}
\hline Publicação & Contexto & Abrangência & Foco \\
\hline $\begin{array}{ll}\text { Fundação } & \text { Carlos } \\
\text { Chagas }(2020) & \end{array}$ & Brasil & Ensino médio e básico & $\begin{array}{l}\text { Novas formas de interação com uso de } \\
\text { tecnologias digitais. Não abordam o } \\
\text { estresse docente. }\end{array}$ \\
\hline $\begin{array}{l}\text { Odriozola-González } \\
\text { et al. (2020) }\end{array}$ & Espanha & $\begin{array}{l}\text { Universidade de } \\
\text { Valladollid }\end{array}$ & Estresse \\
\hline Huang e Zhao (2020) & China & $\begin{array}{l}\text { Professores do ensino } \\
\text { superior, médio e } \\
\text { básico }\end{array}$ & Ansiedade, depressão e qualidade do sono \\
\hline Pather et al. (2020) & $\begin{array}{l}\text { Austrália e Nova } \\
\text { Zelândia }\end{array}$ & 10 universidades & $\begin{array}{l}\text { Percepção de mudanças em práticas } \\
\text { profissionais e de ensino. Não abordam o } \\
\text { estresse docente. }\end{array}$ \\
\hline $\begin{array}{l}\text { Araujo et al. (2020) } \\
\text { (esta pesquisa) }\end{array}$ & Brasil & $\begin{array}{l}\text { Universidades públicas } \\
\text { e privadas em todo o } \\
\text { Brasil }\end{array}$ & $\begin{array}{l}\text { Percepção de estresse entre docentes do } \\
\text { ensino superior na mudança para ensino } \\
\text { remoto durante a pandemia }\end{array}$ \\
\hline
\end{tabular}

\section{Método}

\subsection{Materiais - Construção do instrumento}

Conforme mencionado anteriormente, nesta pesquisa, nosso objetivo é compreender os fatores de estresse relacionados às mudanças urgentes e em caráter de contingência nas práticas de ensino na educação superior decorrentes da pandemia, no Brasil. Nos interessava compreender: a) a ocorrência ou não de sinais de estresse, caracterizando sua intensidade, entre os docentes de ensino superior durante o período de isolamento e migração de aulas remotas; b) as relações entre os níveis de sinais de estresse e outras variáveis relacionadas ao perfil pessoal, atuação docente, contexto de isolamento, experiência com ferramentas e métodos para ensino online e relações de trabalho.

Como instrumento para coleta de dados, optamos por um questionário online, o que nos garantiria alcance e agilidade no levantamento, considerando as limitações para a realização de entrevistas, mesmo virtuais, neste período. O questionário foi estruturado em 7 partes: a) adesão ao termo de consentimento livre e esclarecido; b) dados geográficos (estado, tamanho da cidade); c) dados pessoais (gênero, idade); d) dados profissionais (titulação, área de atuação, tempo de docência, natureza da instituição onde trabalha, carga horária docente); e) contexto de isolamento 
(ocorrência ou não de suspensão de aulas presenciais, período de isolamento, condições de isolamento); f) experiência com docência online e uso de tecnologias (nível de experiência, disponibilidade e adequação de tecnologias e acesso à Internet, quais tecnologias, habilidade no uso de tecnologias, capacitações recebidas, principais dificuldades, busca de ajuda); g) estresse (sinais e sintomas, percepção de estresse relacionada a home-office). A construção deste instrumento está baseada em Carlotto e Palazzo (2006), Faria e Gallo-Penna (2009) e na escolha pelos pesquisadores de sintomas sugestivos de estresse que envolvessem as dimensões mais frequentes: física, psicológica e comportamental.de acordo com diversos estudos na área (Mesquita et al., 2013; Prado, 2016).

\subsection{Participantes da Pesquisa}

Os participantes do estudo foram 456 professores universitários, que estejam ou tenham estado em isolamento social imposto pelo COVID 19 exercendo atividade docente. A escolha dos participantes foi por conveniência. Foram realizados convites para participação via redes sociais e listas de participantes de sociedades científicas. Os participantes puderam enviar o convite a colegas através do compartilhamento do link que dava acesso ao questionário online.

Foram considerados critérios de inclusão: trabalhar como docente em uma instituição de ensino superior na modalidade presencial, estar ou ter passado por isolamento social imposto pelo COVID 19 como professor em atividade no momento da pesquisa. Foram critérios de exclusão do estudo: não aceitar os termos de livre consentimento para a pesquisa, não ter exercido a docência durante o período de isolamento social imposto pelo COVID 19 ou não responder todas as questões do questionário proposto.

\subsection{Procedimento}

Foram realizados convites para participação via redes sociais e listas de participantes de sociedades científicas. Os participantes puderam enviar o convite a colegas através do compartilhamento do link que dava acesso ao questionário online. Ao acessar o link, o participante teve acesso ao questionário online. O questionário foi auto explicativo e levou em média 10 minutos para ser respondido. Primeiramente foram apresentados o estudo e o termo de consentimento livre e esclarecido. O participante teve como opções aceitar ou não participar da pesquisa. Somente após o aceite ele teve acesso às questões. Após responder a todas as questões, o participante foi novamente informado que ao enviar o questionário preenchido ele estaria de acordo em participar da pesquisa. Os dados foram obtidos entre os dias de 07 e 22 de maio de 2020 .

\subsection{Questões Éticas}

O estudo foi aprovado pelo Comitê de Ética em Pesquisa da instituição sede do estudo (CAEE: 31159320.8.0000.0084) e todos os preceitos éticos foram respeitados.

\section{Resultados e Discussões}

Nesta seção, apresentamos as respostas obtidas pelo instrumento de coleta, de acordo com as dimensões de análise esperadas e nossas discussões a partir dos dados levantados.

\subsection{Cenário nacional durante a pesquisa}

O primeiro caso de COVID-19 no Brasil foi reportado no final de fevereiro de $2020^{1}$, enquanto acompanhávamos a progressão da pandemia na China e nos países da Europa. A cidade de São

${ }^{1}$ Cronologia da COVID-19 no Brasil. https://www.dw.com/pt-br/cronologia-da-covid-19-no-brasil/g-52930927 
Paulo se tornou o epicentro da epidemia no país, registrando a primeira morte em meados de março. Antes do final deste mesmo mês, todos os estados brasileiros já registravam confirmações de cidadãos infectados. A epidemia, em um mês, alcançou todo o território nacional. $\mathrm{O}$ país começa a reagir aos efeitos da pandemia ao final de mês de março, com o fechamento de fronteiras, mas uma atitude incrédula do Governo Federal, com uma preocupação primordial à estabilidade econômica, provoca uma série de acontecimentos que vieram a culminar, até o momento de escrita deste artigo, com mais de 2 milhões de pessoas infectadas, e pelo menos 80.000 mortes registradas em território nacional ${ }^{2}$.

O isolamento social é decretado em março, com autonomia de aplicação pelos estados, mas, ainda em abril, uma grande pressão do Governo Federal para a saída do isolamento se faz sentir, incluindo a opção de uso de drogas ainda duvidosas no combate à doença. O combate à epidemia do novo coronavírus no Brasil foi marcado por um embate ideológico interno entre Governo Federal e Estados da Federação e na estrutura interna do próprio governo, com trocas sucessivas de Ministros da Saúde (um ministro se retira em abril, outro se retira em maio). Em maio, o Brasil alcança a marca de 2 o país com maior número de casos de COVID-19 no mundo e, no início de junho, torna-se o terceiro país com maior número de mortes, apesar dos evidentes subregistros de casos em todo o país.

O Ministério da Educação, em 17 de março (Brasil, 2020), autoriza a suspensão de aulas presenciais nas instituições de ensino superior e sua substituição por aulas mediadas por tecnologia, de acordo com a disponibilidade das universidades, pelo prazo de 30 dias, posteriormente prorrogados por mais 30 dias (Brasil, 2020a) e, em junho, uma nova prorrogação (Brasil 2020b) autoriza a substituição até dezembro de 2020.

Este era o cenário de conjuntura nacional quando os dados desta pesquisa foram levantados (07 a 22 de maio) - franco alastramento da epidemia no cenário nacional; isolamento social; fragmentação ideológica levando a conflitos e incertezas nas estratégias de combate à pandemia pelos órgãos de governo e nas respostas da sociedade às ações promulgadas; instabilidade institucional no Governo Federal (incluindo sucessivas alterações no Ministério da Educação); descaso frente ao panorama de mortes (o que inclui frases do presidente minimizando o quadro); emergência na transição de aulas presenciais para aulas mediadas por tecnologia, a cargo das universidades; e incertezas quanto ao prazo para retorno às aulas presenciais, com sucessivas prorrogações pelo Ministério da Educação.

\subsection{Perfil dos respondentes}

Dos 456 participantes que responderam à pesquisa, 245 se identificam como sendo do gênero feminino e 210 do gênero masculino e 1 participante não quis informar o gênero. Em relação à idade, $2,41 \%$ têm menos de 30 anos, $22,37 \%$ têm entre 30 e 39 anos, $42,76 \%$ têm entre 40 e 50 anos e 32,46\% responderam ter mais de 50 anos. Deste total, 189 (aproximadamente 41,4\%) são professores de universidades públicas, 239 (aproximadamente 52,4\%) de universidades particulares e 28 (aproximadamente 6,1\%) são professores em ambas. Em relação ao tempo de docência, $12,72 \%$ tem menos de cinco anos, $18,86 \%$ entre cinco e nove anos, $34,65 \%$ entre 10 a 19 anos e 33,77\% têm 20 anos ou mais. Sobre a carga horária semanal, 4,17\% dos respondentes disseram ter menos de 8 horas semanais, $16,45 \%$ entre 8 e 19 horas, 52,19\% entre 20 e 40 horas e $27,19 \%$ acima de 40 horas. Esses dados estão sintetizados no infográfico da Figura 1:

\footnotetext{
${ }^{2}$ Bing. Coronavirus Brazil, https://www.bing.com/covid/local/brazil
} 


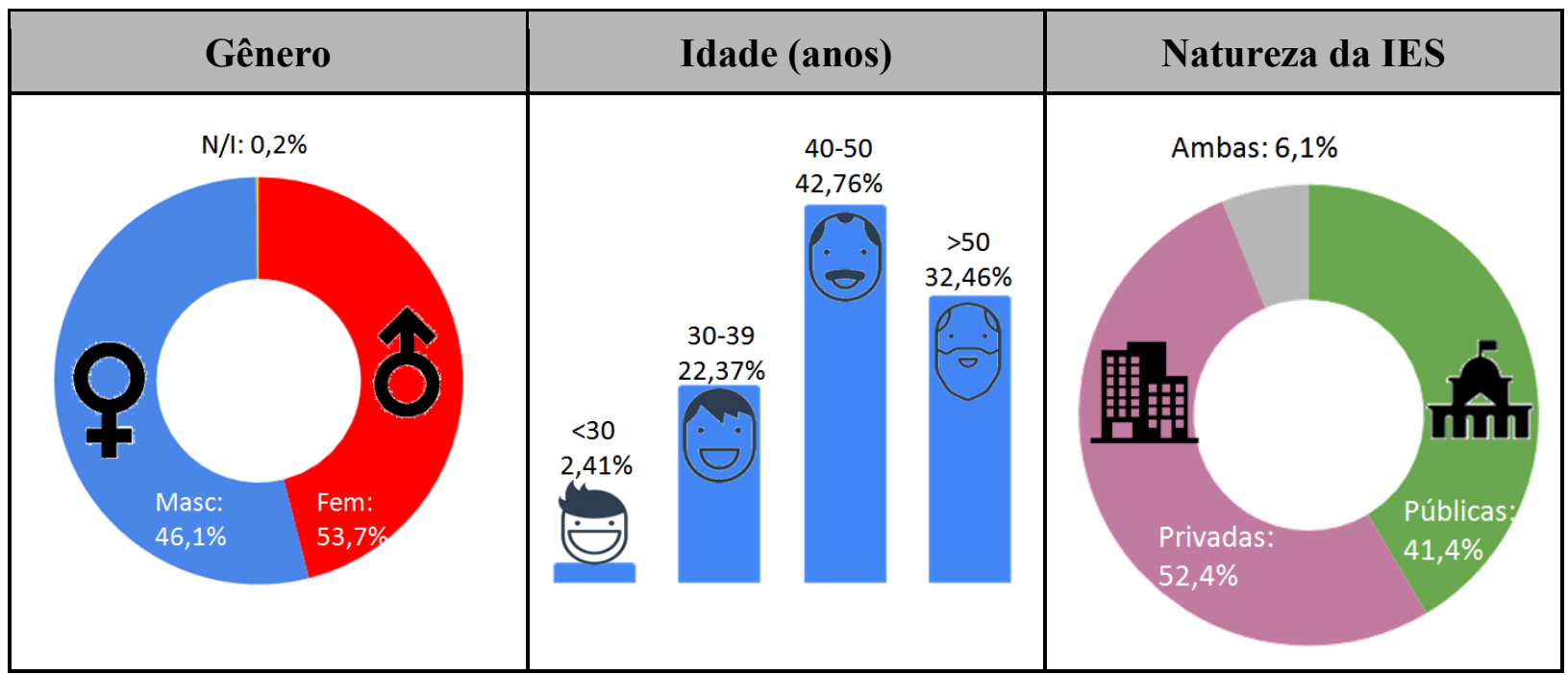

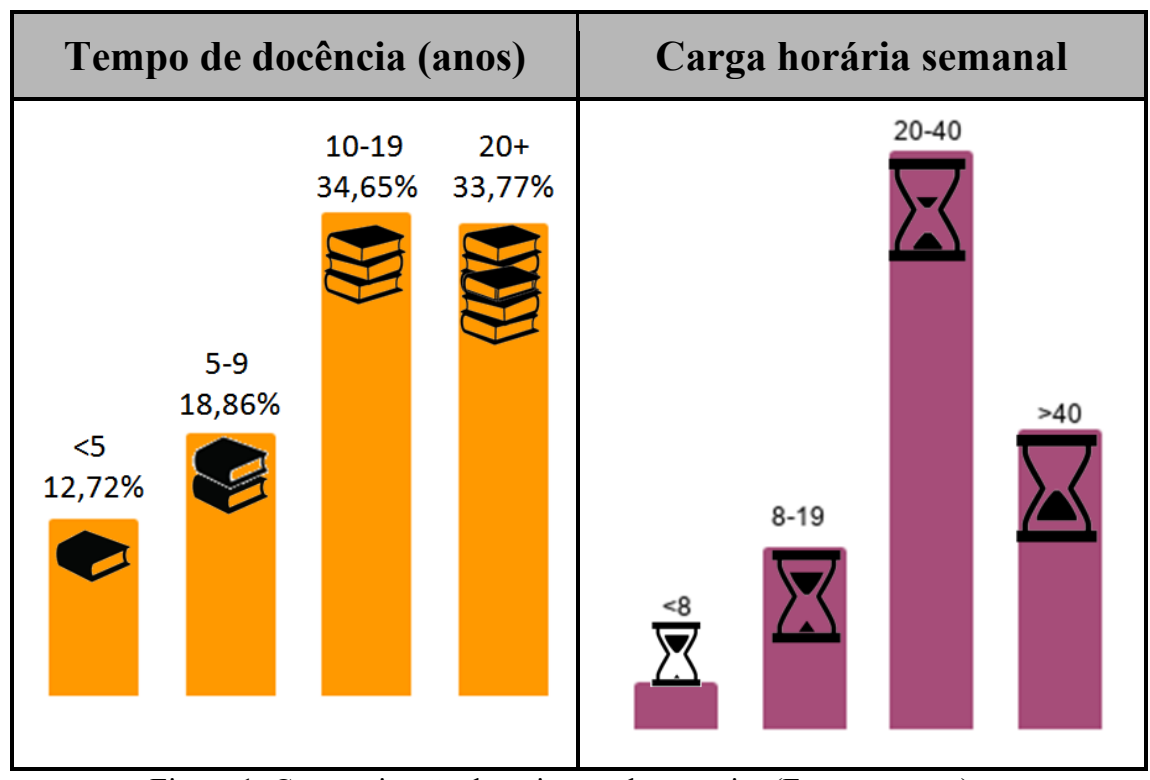

Figura 1: Caracterização do universo da pesquisa (Fonte: autores)

Em relação à titulação e gênero, a Figura 2 mostra que a maioria dos respondentes possuem doutorado com maior titulação $(59,43 \%)$ e são mulheres $(31,80 \%) .32 \%$ são mestres e apenas $8,12 \%$ são especialistas. 


\section{Maior Titulação}

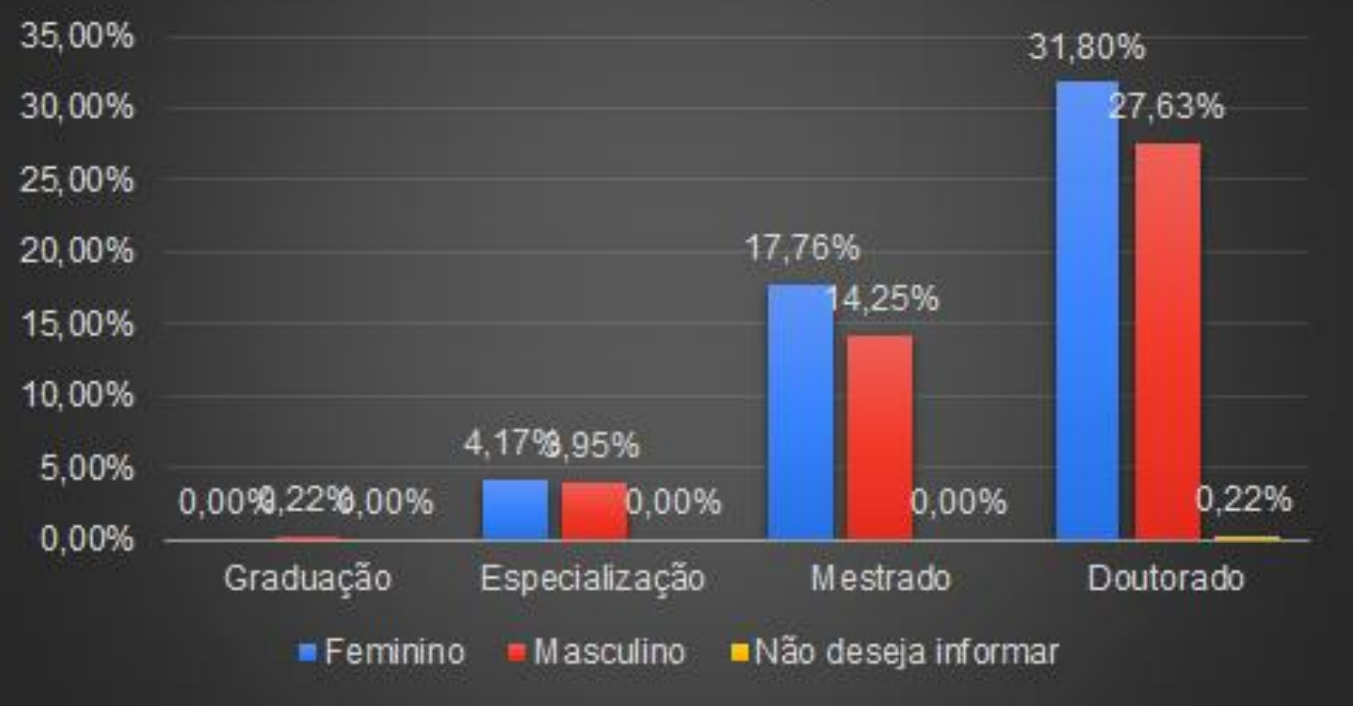

Figura 2: Titulação dos participantes e correspondência com o gênero (Fonte: autores)

Em relação à área de atuação, a Figura 3 apresenta os dados comparativamente com o gênero. Observa-se que 35,75\% dos respondentes atuam na área de Ciências Exatas e da Terra, com predominância de homens e 21,93\% atuam na área de Ciências da Saúde, com predominância de mulheres.

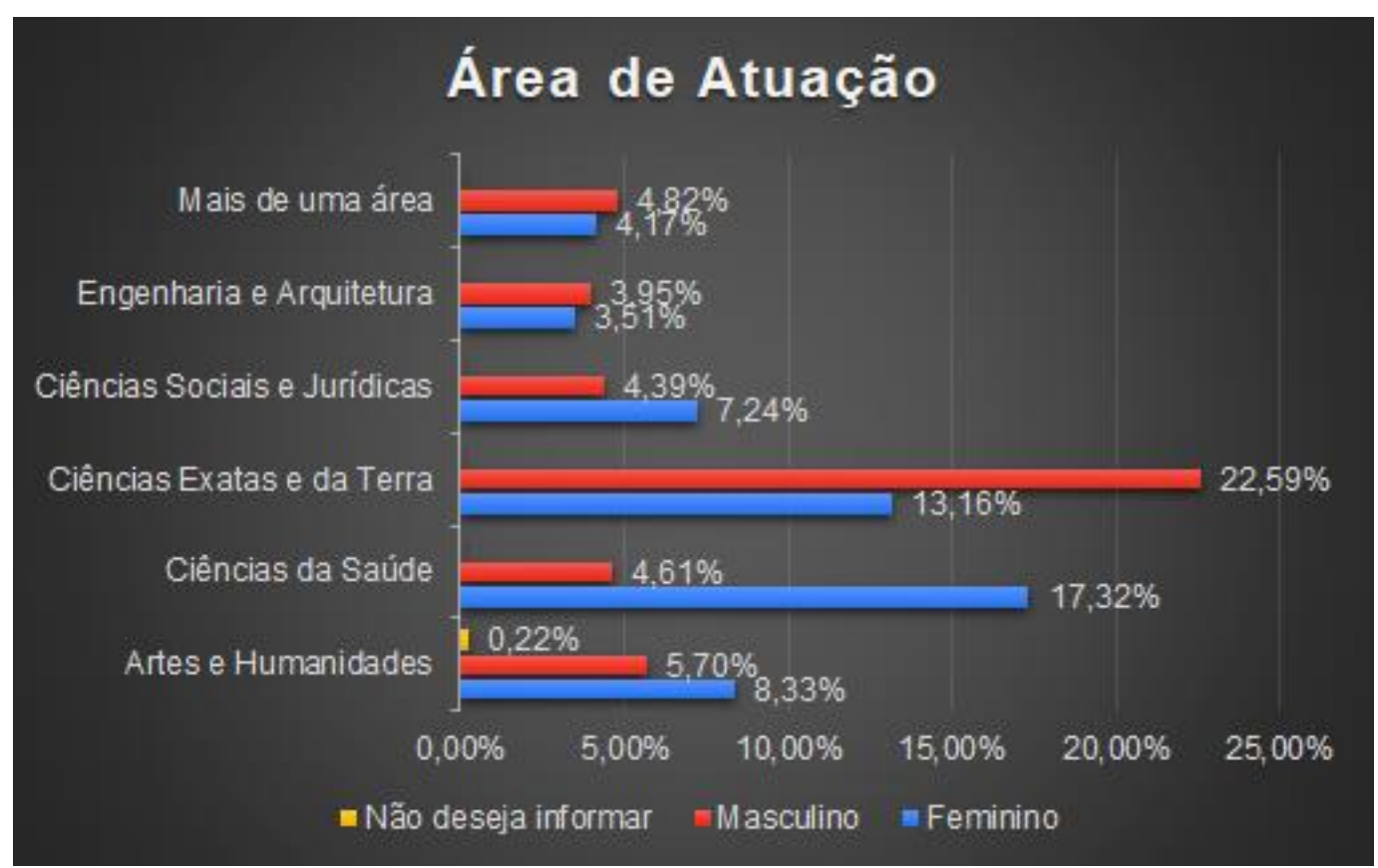

Figura 3: Área de atuação dos participantes e correspondência com o gênero (Fonte: autores)

Em relação aos dados geográficos, a Figura 4 apresenta a distribuição da quantidade de respondentes por estado brasileiro, onde observa-se a participação de respondentes em quase todos os Estados do Brasil, com predominância do Estado de São Paulo, com 191 respondentes, seguido pelo Estado do Rio de Janeiro com 52. Apenas três estados brasileiros (Acre, Roraima e Amapá) não participaram da pesquisa. 


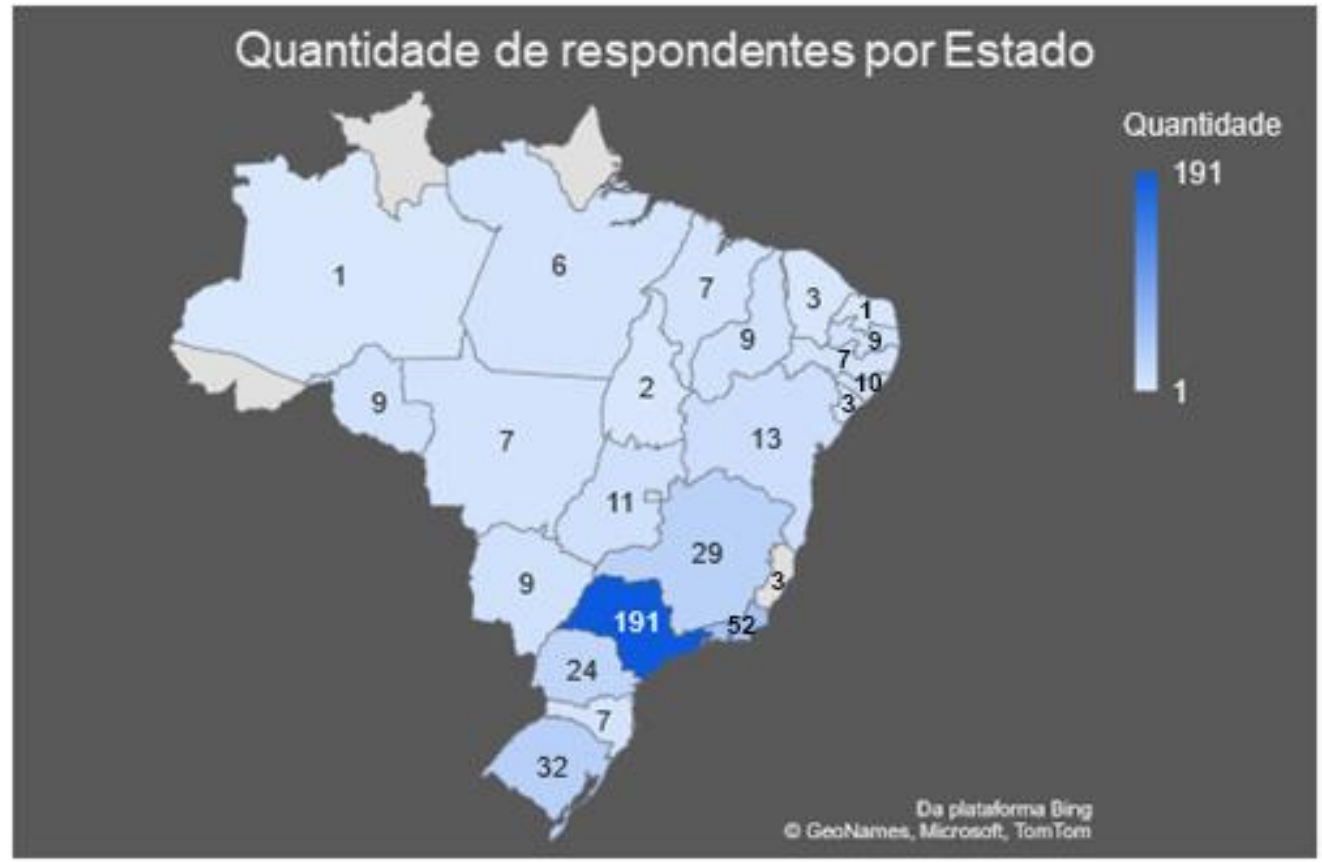

Figura 4. Distribuição da Quantidade de respondentes pelos Estados Brasileiros (Fonte: autores)

A Figura 5 apresenta a porcentagem dos respondentes por tamanho de cidade. Observa-se que $62,56 \%$ atuam em cidades com mais de 500 mil habitantes e apenas $6,17 \%$ atuam em cidades com 50 mil a 100 mil habitantes $7,93 \%$ atuam em cidades pequenas, com menos de 50 mil habitantes.

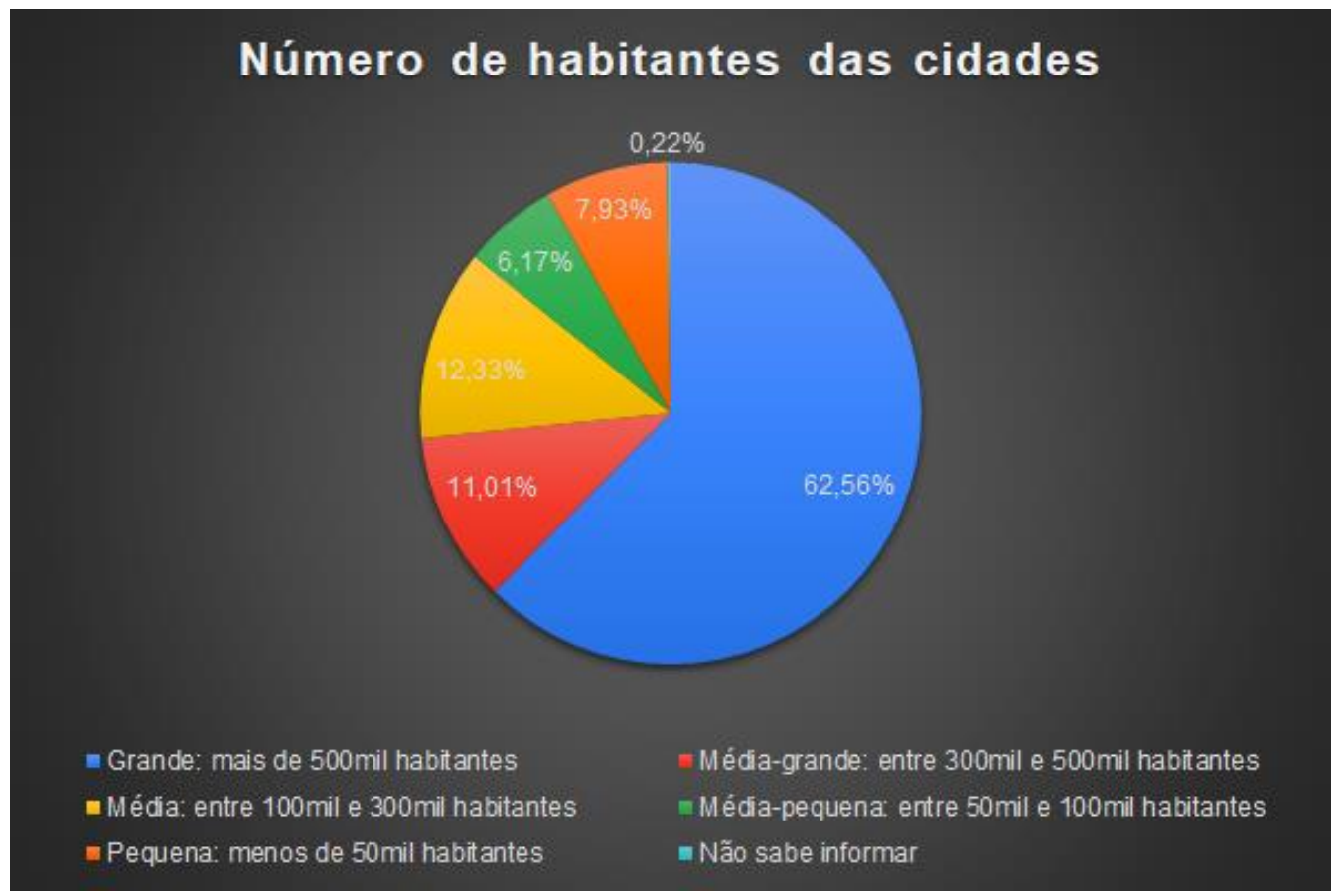

Figura 5: Tamanho das Cidades dos Respondentes (Fonte: autores)

48 professores mencionaram que não estão tendo experiências docentes remotas mediadas por tecnologia durante o período de isolamento social; 14 disseram que suas atividades presenciais 
não foram suspensas. Os dados destes participantes foram retirados da base de dados, restando 394 participantes, que será considerado agora o número total de participantes.

394 participantes estão tendo atividades docentes remotas medidas por tecnologia, ou seja, $79,46 \%$ dos participantes do universo inicial da pesquisa. A maioria dos respondentes $(85,79 \%)$ está passando o período de isolamento social com a família, seguido por $10,15 \%$ dos respondentes que está sozinho, com amigos $(1,27 \%)$ e outros $(2,79 \%)$.

\subsection{Experiência em docência online e uso de tecnologias}

$62,44 \%$ dos participantes declararam que já tinham tido experiências docentes remotas mediadas por tecnologia, antes do isolamento social. De acordo com os participantes da pesquisa sobre o seu nível de habilidade com o uso de equipamentos (computadores, tablets ou celulares) e softwares em geral, percebe-se uma grande maioria (67\%) que se declara com muito alta ou alta habilidade, tal como é apresentado na Figura 6.

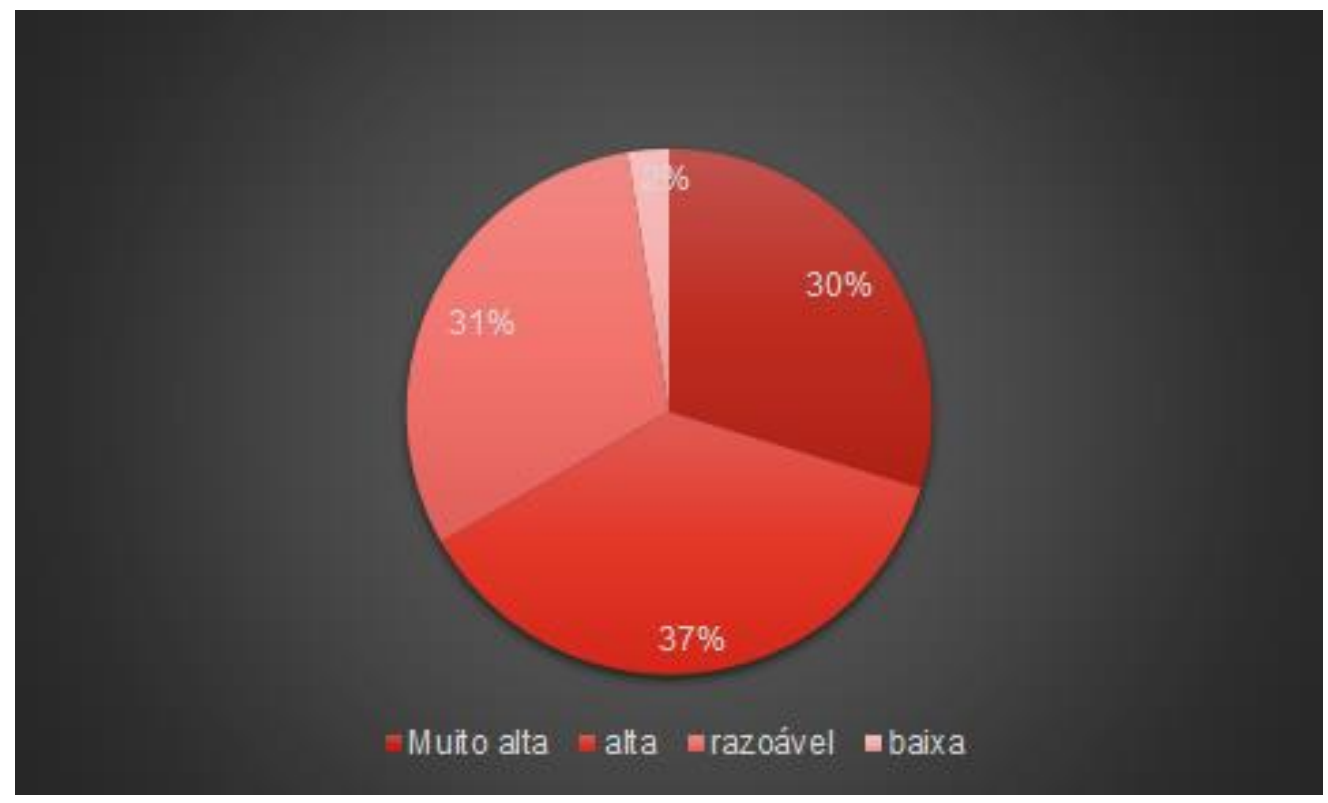

Figura 6. Nível de habilidade com o uso de equipamentos e software (Fonte: autores)

Em relação aos equipamentos (computadores, celulares, tablets etc.), a maioria $(88,07 \%)$ dos participantes disse ter equipamento para uso exclusivo, enquanto $11,93 \%$ compartilham seus equipamentos com a família. A quase totalidade $(92,64 \%)$ considera que os equipamentos que usa são apropriados para a realização das atividades de trabalho. Igualmente foi a resposta $(92,64 \%)$ em relação a ter acesso adequado à Internet em casa para realizar as atividades de trabalho.

Quando questionados em relação à aquisição de tecnologias para suas atividades de trabalho durante o isolamento social, $28,43 \%$ dos respondentes disseram ter adquirido algum tipo de tecnologia. Entre as mais adquiridas estão: equipamentos (computador, notebooks) e atualização de equipamentos; sistemas de videoconferência, tais como Zoom; contratação de Internet de maior velocidade; equipamentos periféricos, tais como mesa digitalizadora, microfone, mouse, lousa digital, webcam; software tais como gravadores de tela, editor de vídeo.

Em relação às ferramentas digitais utilizadas antes do isolamento social e por decorrência dele, a Figura 7 mostra claramente um aumento significativo no uso das ferramentas Microsoft Teams e Zoom em decorrência do ensino remoto. As ferramentas da Google (Hangouts/Meet e Classroom) também apresentaram um aumento em seu uso, embora mais discreto. Possivelmente, o aumento do uso do Teams deve-se a ações institucionais, enquanto o aumento percebido nas ferramentas Zoom e Google Meet possivelmente deve-se à gratuidade em seu uso, aliado também 
a iniciativas institucionais - com assinaturas institucionais do Zoom ou adoção de soluções relacionadas ao Google Classroom.

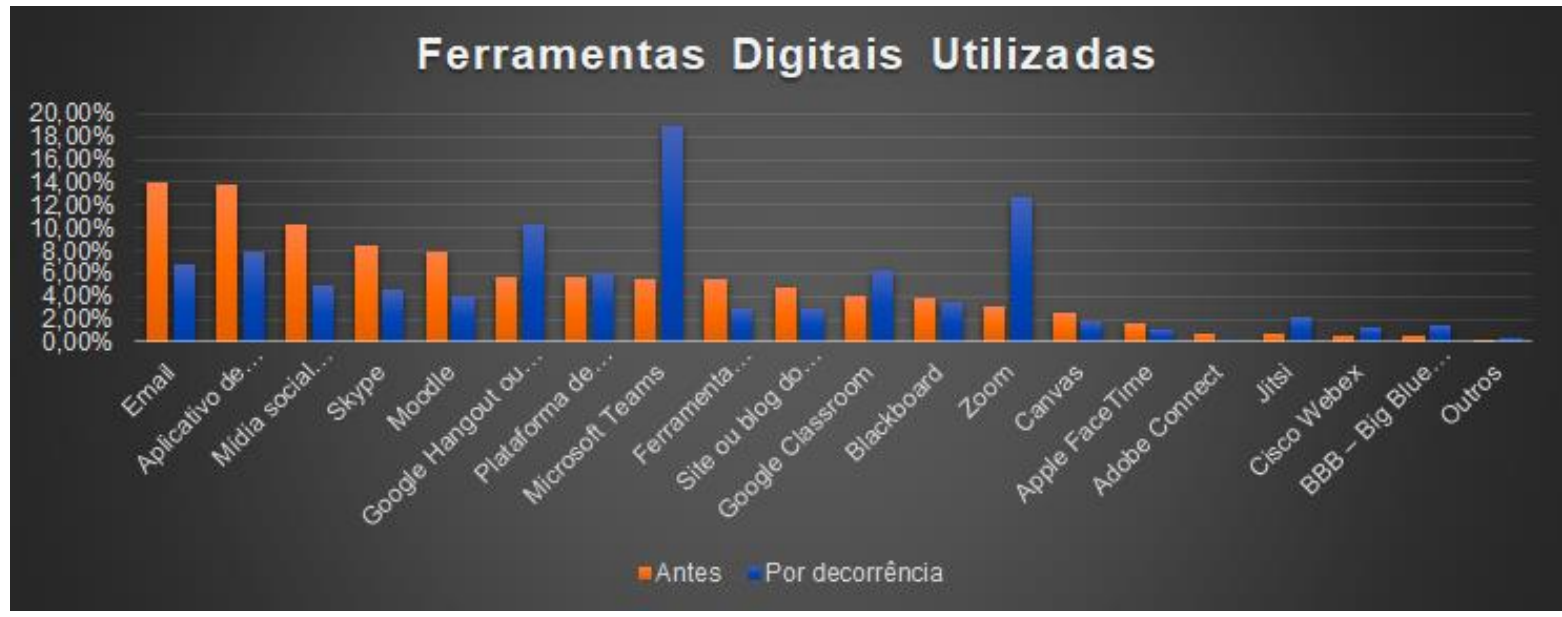

Figura 7. Ferramentas digitais utilizadas antes e por decorrência do isolamento social (Fonte: autores)

Em relação a dificuldades na prática docente, 54,31\% dos respondentes disseram não ter enfrentado problemas com o uso de ferramentas digitais e/ou com metodologias de ensinoaprendizagem no ambiente virtual. Entre as principais dificuldades apontadas pelos professores, estão: falta de capacitação adequada para utilização de ferramentas digitais e metodologias, instabilidade de conexão com a Internet/ plano de acesso à internet insuficiente, interação/engajamento menor com os estudantes por decorrência de metodologias inapropriadas, aumento excessivo da carga de trabalho para adequar o material (digital) e dar assistência aos alunos, impossibilidade de realização de aulas práticas, entre outros.

\subsection{Percepção de estresse}

Em relação às sete variáveis que podem indicar estresse e o gênero, foram encontrados os seguintes resultados: há uma predominância acentuada na percepção dos fatores de estresse nas professoras, em relação aos professores, como mostram a Figura 8 e Tabela 2; o participante que não quis identificar seu gênero, não apresentou nenhuma das dimensões relacionadas ao estresse, como mostra a Tabela 2.

Estes resultados corroboram com estudos que apontam que as mulheres apresentam mais sintomas de estresse que os homens. De acordo com os estudiosos do tema as mulheres apresentam sintomas com amplitude maior de intensidade e de variedade. Alguns sintomas estão relacionados a aspectos de sua própria físiologia como espinhas, dor pélvica, pele ressecada, cólica menstrual (Calais, Andrade \& Lipp, 2003; Fogaça et al., 2010). Com relação ao estresse ocupacional do docente também há estudos que identificaram que as professoras estão mais propensas a ter sintomas de estresse que os professores. Isso pode estar relacionado ao acúmulo de funções domésticas (cuidados com o lar e com os filhos), geralmente associado às mulheres em sociedades em que há um forte componente cultural machista - como a brasileira (Martins, 2007; Goulart Junior \& Lipp, 2008; Sadir, Bignotto \& Lipp, 2010). 


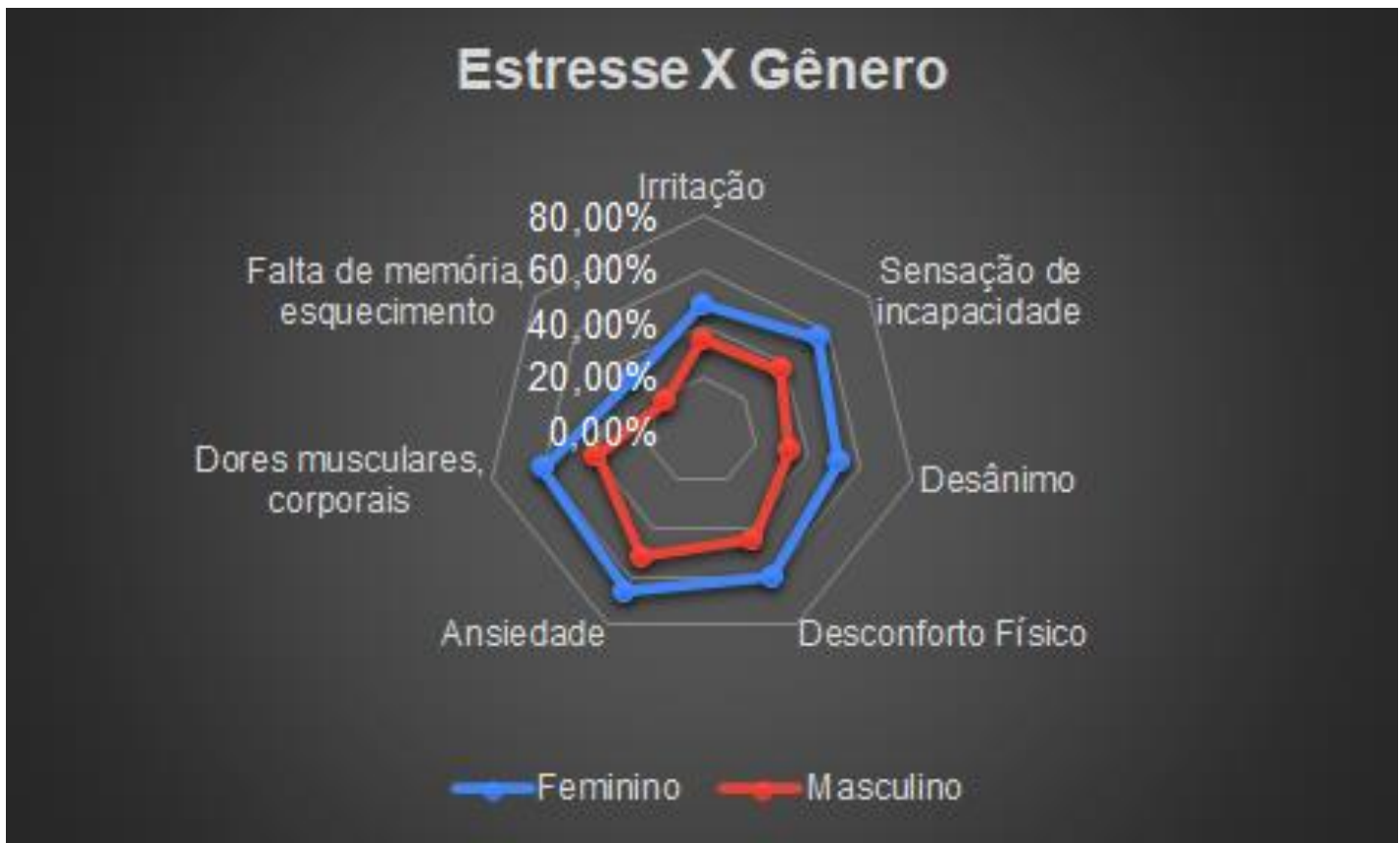

Figura 8. As sete dimensões de Estresse relacionadas ao Gênero (Fonte: autores)

Tabela 2: Relação entre Estresse e Gênero

\begin{tabular}{|c|c|c|c|c|c|c|c|}
\hline Gênero & Irritação & $\begin{array}{l}\text { Sensação de } \\
\text { incapacidade }\end{array}$ & Desânimo & $\begin{array}{l}\text { Desconforto } \\
\text { físico }\end{array}$ & Ansiedade & $\begin{array}{l}\text { Dores } \\
\text { musculares }\end{array}$ & $\begin{array}{l}\text { Falta de } \\
\text { memória }\end{array}$ \\
\hline Feminino & $47,22 \%$ & $55,56 \%$ & $52,31 \%$ & $60,19 \%$ & $65,74 \%$ & $60,65 \%$ & $32,41 \%$ \\
\hline Masculino & $34,46 \%$ & $37,29 \%$ & $33,33 \%$ & $44,63 \%$ & $51,41 \%$ & $40,11 \%$ & $17,51 \%$ \\
\hline $\begin{array}{l}\text { Não desejo } \\
\text { informar }\end{array}$ & 0 & 0 & 0 & 0 & 0 & 0 & 0 \\
\hline
\end{tabular}

A Figura 9 e a Tabela 3 apresentam os dados referentes à relação entre estresse e área de atuação do participante. Observa-se que os fatores de estresse são mais presentes em professores que atuam em cursos da grande área de Ciências Sociais e Jurídicas, seguidos pelos professores da área de Ciências da Saúde, e menos presentes em professores da área de Artes e Humanidades ou que atuam em mais de uma área. Este resultado se contrapõe ao encontrado nos estudos de Odriozola-González et al. (2020), em Valladolid, Espanha, que, embora não comparáveis em termos de amostra e em diferentes contextos, pode sugerir a ausência de um padrão de percepção de estresse em relação à área de atuação docente.

Pistone (2005) aponta para uma indiferença geral quanto ao impacto das tecnologias digitais nos cursos de Direito no contexto dos Estados Unidos - cenário este que não difere muito da situação nacional. Possivelmente por acumularem cargos na área jurídica, em geral acostumados com a disponibilidade de assessorias, a necessidade de apropriação dos saberes tecnológicos - sem assessores para ajudar - trazida pela emergência não apenas das aulas remotas, mas também do crescente número de processos jurídicos que surgem da adoção das tecnologias - como apontado por Mezzarroba et al. (2014), ou que por elas são causadas, gera um conjunto de novas exigências 
a esses profissionais. Junte-se a isso a frequência cada vez maior de novos estudantes com vivências e expectativas digitais, como já apontado por Thomson (2009).

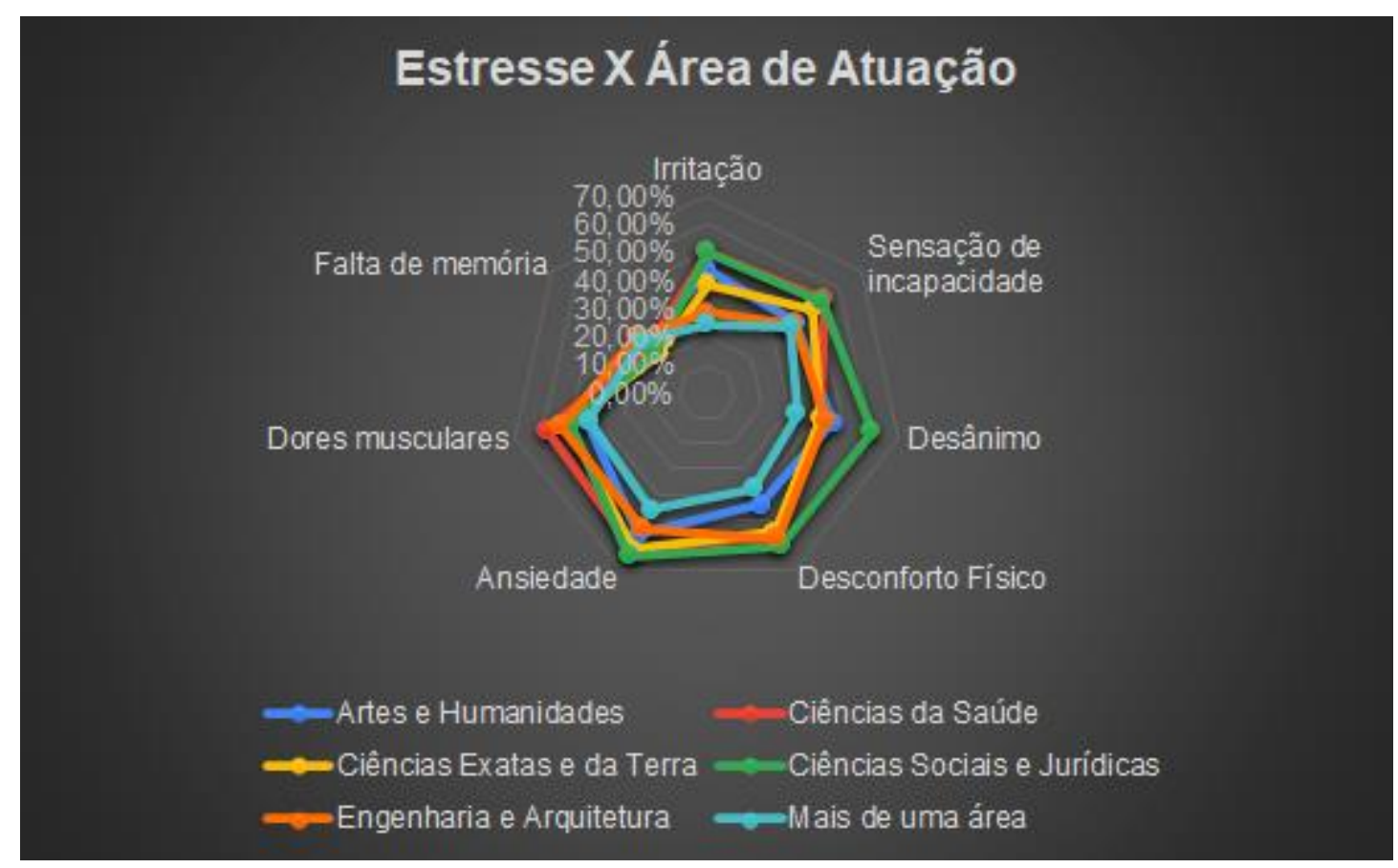

Figura 9. As sete dimensões de Estresse relacionadas à área de atuação docente (Fonte: autores)

Tabela 3: Relação entre Estresse e Área de Atuação

\begin{tabular}{|c|c|c|c|c|c|c|c|}
\hline & Irritação & $\begin{array}{l}\text { Sensação de } \\
\text { Incapacidade }\end{array}$ & Desânimo & $\begin{array}{l}\text { Desconforto } \\
\text { Físico }\end{array}$ & Ansiedade & $\begin{array}{l}\text { Dores } \\
\text { Musculares }\end{array}$ & $\begin{array}{l}\text { Falta de } \\
\text { Memória }\end{array}$ \\
\hline $\begin{array}{l}\text { Artes e } \\
\text { Humanidades }\end{array}$ & $44,00 \%$ & $40,00 \%$ & $46,00 \%$ & $44,00 \%$ & $56,00 \%$ & $44,00 \%$ & $28,00 \%$ \\
\hline $\begin{array}{l}\text { Ciências da } \\
\text { Saúde }\end{array}$ & $50,00 \%$ & $53,19 \%$ & $41,49 \%$ & $56,38 \%$ & $61,70 \%$ & $58,51 \%$ & $26,60 \%$ \\
\hline $\begin{array}{l}\text { Ciências } \\
\text { Exatas e da } \\
\text { Terra }\end{array}$ & $38,52 \%$ & $48,15 \%$ & $41,48 \%$ & $54,81 \%$ & $61,48 \%$ & $51,11 \%$ & $22,22 \%$ \\
\hline $\begin{array}{l}\text { Ciências } \\
\text { Sociais } \\
\text { Jurídicas }\end{array}$ & $50,00 \%$ & $52,00 \%$ & $60,00 \%$ & $60,00 \%$ & $64,00 \%$ & $50,00 \%$ & $24,00 \%$ \\
\hline $\begin{array}{l}\text { Engenharia e } \\
\text { Arquitetura }\end{array}$ & $28,57 \%$ & $39,29 \%$ & $42,86 \%$ & $57,14 \%$ & $53,57 \%$ & $53,57 \%$ & $32,14 \%$ \\
\hline $\begin{array}{l}\text { Mais de uma } \\
\text { Área }\end{array}$ & $24,32 \%$ & $37,84 \%$ & $32,43 \%$ & $37,84 \%$ & $45,95 \%$ & $43,24 \%$ & $29,73 \%$ \\
\hline
\end{tabular}


Os professores da área de saúde, somam a prática docente a prática assistencial, com supervisão de estágios, clínicas escolas, orientação a alunos. Nestas situações precisam lidar com conceitos teóricos de promoção de saúde e adoecimento, que muitas vezes não são transportados para a esfera prática. Ensinam sobre a saúde, mas, muitas vezes, em condições pouco saudáveis (Miranda, Pereira \& Passos, 2009; Leite \& Nogueira, 2017). Outro dado levantado por autores como justificativa a presença de sintomas de estresse entre os professores da área da saúde é a prevalência de docentes mulheres em diversas carreiras da área da saúde (Oliveira et al., 2012; Gomes \& Caetano, 2014; Sá et al., 2018).

Em relação às sete variáveis que podem indicar estresse e as habilidades dos participantes com o uso de equipamentos (computadores, tablets ou celulares) e softwares em geral, houve uma forte correlação inversa entre os fatores de estresse e a habilidade autopercebida com tecnologias digitais, como mostram a Figura 10 e a Tabela 4, em especial no que se refere ao desânimo e à sensação de incapacidade - este último fator pode dever-se à insegurança para o uso pleno de tecnologias digitais no fazer docente, mas também pode apontar para uma necessidade de aprimoramento na experiência de usuário proporcionada atualmente pelas ferramentas mais utilizadas. Além disso, há uma grande expectativa em relação ao uso adequado da tecnologia e à sua disponibilidade, por parte do professor, que muitas vezes não foi correspondida devido à infraestrutura da instituição de ensino que não estava preparada para uma demanda tão grande, o leva à ansiedade e reforça o desânimo e a sensação de incapacidade (Sá et al., 2018; Poalses \& Bezuidenhout, 2018; Pather et al., 2020; Sahu, 2020). Em nenhum outro momento houve tantos acessos simultâneos sobrecarregando a Internet (com aulas online, home office, serviços de streaming e videoconferências) e nem uma necessidade de armazenar tantas informações no servidor provenientes de conteúdos e atividades pedagógicas. As operadoras de telecomunicações do Brasil viram o tráfego de banda larga fixa aumentar entre $40 \%$ e $50 \%$ desde o início da pandemia ${ }^{3}$.

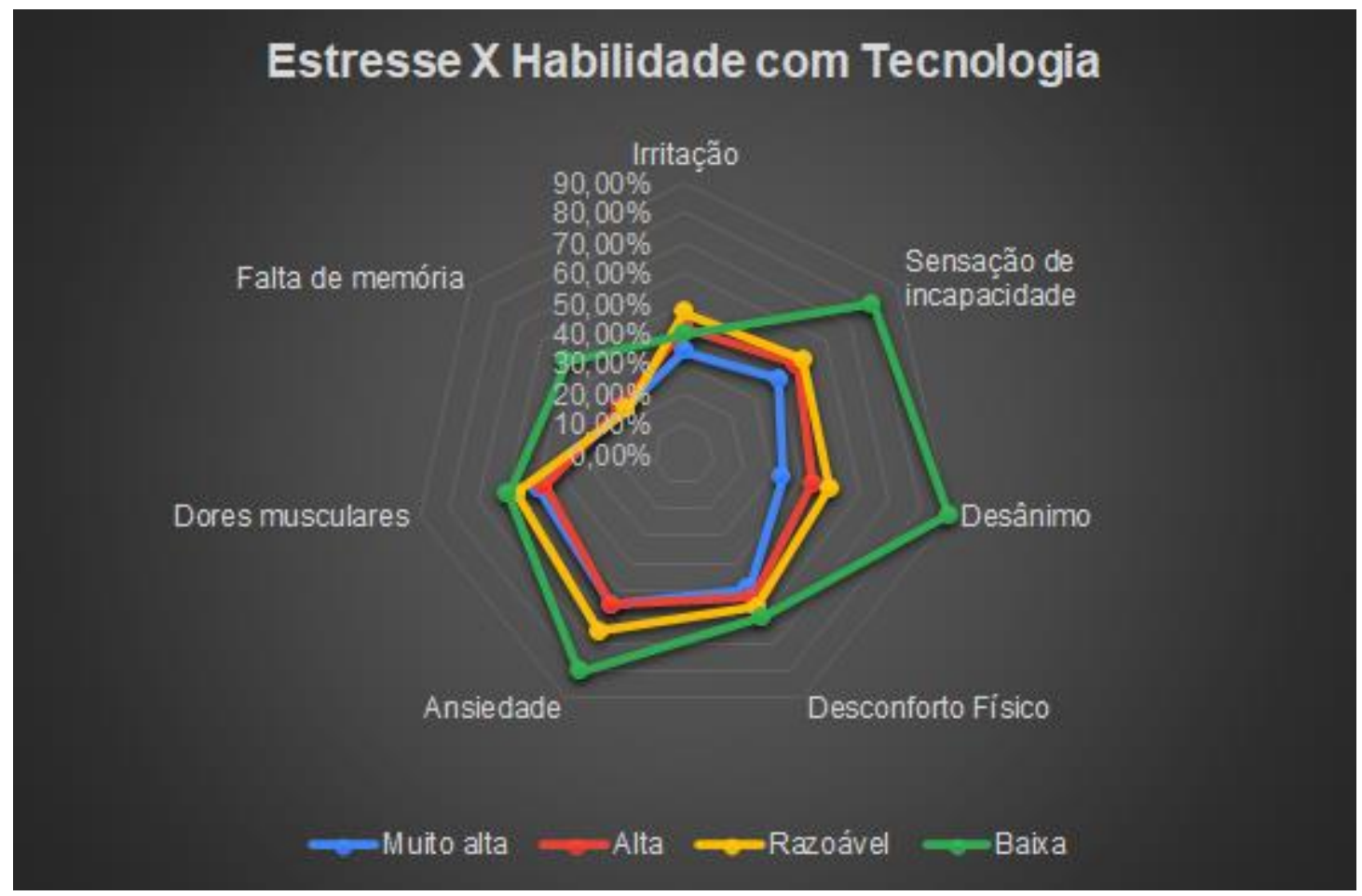

Figura 10. As sete dimensões de Estresse relacionadas à Habilidade com Tecnologia (Fonte: autores)

\footnotetext{
3 Anatel diz que Covid-19 explodiu tráfego de banda larga e atrasa 5G no país... - Veja mais em https://www.uol.com.br/tilt/noticias/reuters/2020/05/22/anatel-ve-covid-19-impulsionar-banda-larga-admite-atrasoem-leilao-5g.htm?cmpid=copiaecola $(22 / 05 / 2020)$
} 
Tabela 4: Relação entre Estresse e Habilidade com Tecnologia

\begin{tabular}{|c|c|c|c|c|c|c|c|}
\hline & Irritação & $\begin{array}{l}\text { Sensação de } \\
\text { incapacidade }\end{array}$ & Desânimo & $\begin{array}{l}\text { Desconforto } \\
\text { físico }\end{array}$ & Ansiedade & $\begin{array}{l}\text { Dores } \\
\text { musculares }\end{array}$ & $\begin{array}{l}\text { Falta de } \\
\text { memória }\end{array}$ \\
\hline Muito alta & $34,19 \%$ & $40,17 \%$ & $33,33 \%$ & $49,57 \%$ & $55,56 \%$ & $49,57 \%$ & $24,79 \%$ \\
\hline Alta & $42,47 \%$ & $47,95 \%$ & $43,84 \%$ & $52,74 \%$ & $55,48 \%$ & $47,26 \%$ & $26,03 \%$ \\
\hline Razoável & $47,11 \%$ & $50,41 \%$ & $49,59 \%$ & $56,20 \%$ & $65,29 \%$ & $57,02 \%$ & $23,97 \%$ \\
\hline Baixa & $40,00 \%$ & $80,00 \%$ & $90,00 \%$ & $60,00 \%$ & $80,00 \%$ & $60,00 \%$ & $50,00 \%$ \\
\hline
\end{tabular}

Para medir se os participantes que vivem em diferentes tamanhos de cidades estão mais ou menos suscetíveis ao estresse, foram relacionadas as sete variáveis que indicam estresse com o tamanho das cidades, conforme a Figura 11 e a Tabela 5. O único participante que não soube enquadrar o tamanho de sua cidade, está sendo afetado por irritação, sensação de incapacidade, desânimo, desconforto físico e ansiedade. Os resultados mostram que há uma discreta preponderância de fatores de estresse em professores que habitam cidades consideradas médiaspequenas, com um destaque para uma maior percepção de desânimo entre os habitantes das cidades menores. $\mathrm{O}$ acesso mais precário a recursos tecnológicos, entre os quais banda larga, pode estar entre os fatores que explicam este aspecto.

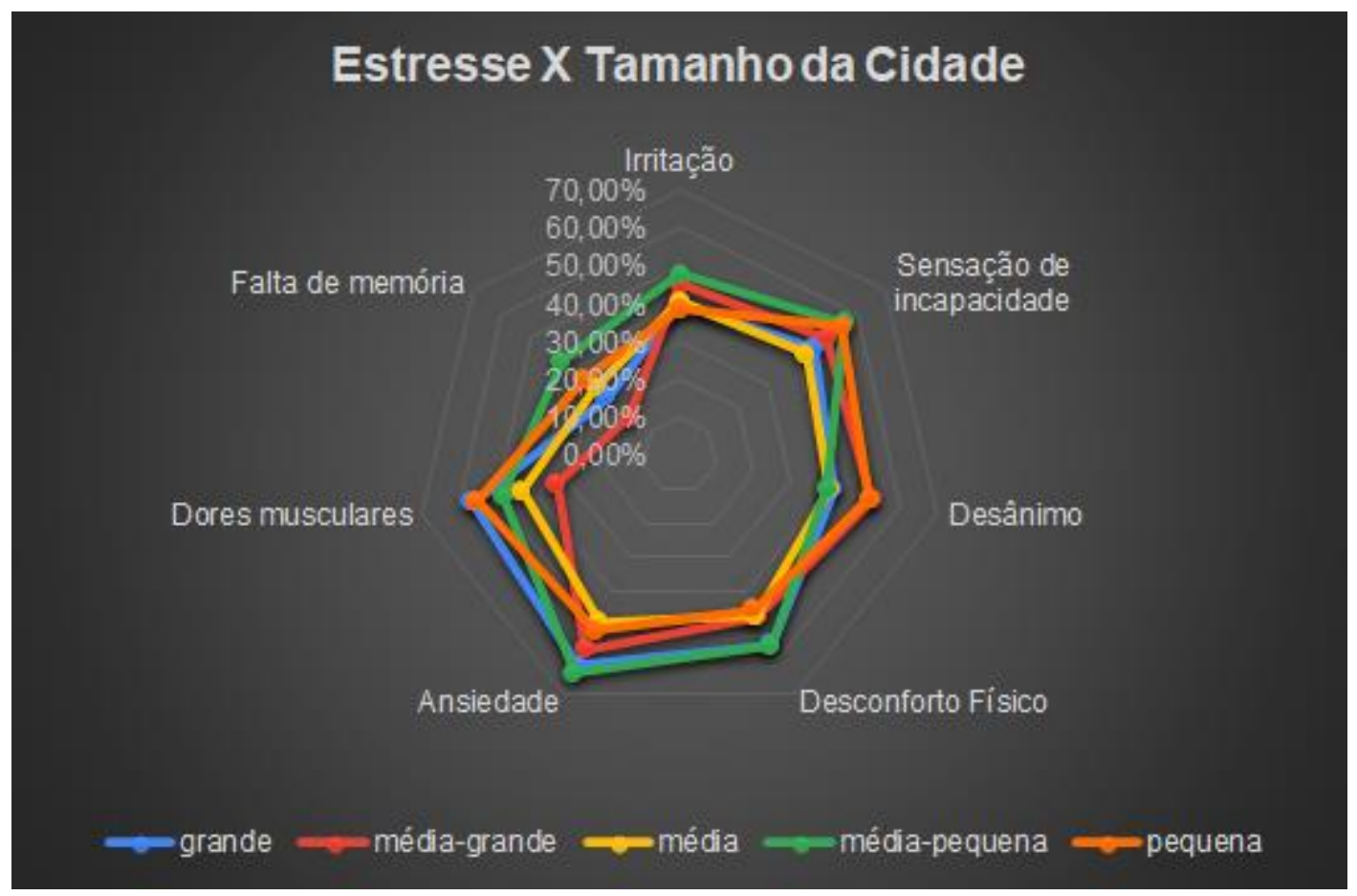

Figura 11. As sete dimensões de Estresse relacionadas ao Tamanho da Cidade dos Participantes (Fonte: autores) 
Tabela 5: Relação entre Estresse e Tamanho da Cidade

\begin{tabular}{|c|c|c|c|c|c|c|c|}
\hline & Irritação & $\begin{array}{l}\text { Sensação de } \\
\text { incapacidade }\end{array}$ & Desânimo & $\begin{array}{l}\text { Desconforto } \\
\text { físico }\end{array}$ & Ansiedade & $\begin{array}{l}\text { Dores } \\
\text { musculares }\end{array}$ & $\begin{array}{l}\text { Falta de } \\
\text { memória }\end{array}$ \\
\hline Grande & $40,41 \%$ & $45,71 \%$ & $41,63 \%$ & $55,51 \%$ & $61,63 \%$ & $56,33 \%$ & $24,49 \%$ \\
\hline $\begin{array}{l}\text { Média- } \\
\text { grande }\end{array}$ & $45,24 \%$ & $50,00 \%$ & $52,38 \%$ & $47,62 \%$ & $57,14 \%$ & $33,33 \%$ & $16,67 \%$ \\
\hline Média & $40,82 \%$ & $42,86 \%$ & $40,82 \%$ & $46,94 \%$ & $48,98 \%$ & $42,86 \%$ & $28,57 \%$ \\
\hline $\begin{array}{l}\text { Média- } \\
\text { pequena }\end{array}$ & $48,00 \%$ & $56,00 \%$ & $40,00 \%$ & $56,00 \%$ & $64,00 \%$ & $48,00 \%$ & $40,00 \%$ \\
\hline Pequena & $38,71 \%$ & $54,84 \%$ & $51,61 \%$ & $45,16 \%$ & $51,61 \%$ & $54,84 \%$ & $32,26 \%$ \\
\hline $\begin{array}{l}\text { Não sei } \\
\text { informar }\end{array}$ & 1 & 1 & 1 & 1 & 1 & 0 & 0 \\
\hline
\end{tabular}

Por outro lado, para medir se participantes que tiveram capacitação para ministrar aulas em modo não presencial antes ou em decorrência do isolamento social estavam mais ou menos suscetíveis ao estresse, foram relacionadas as sete variáveis que caracterizam estresse com participantes que tiveram capacitação nestes dois momentos, tais como apresentam as Figuras 12 e 13 e a Tabela 6. Não foi verificada diferença significativa em relação aos fatores de estresse entre os que receberam capacitação para o uso de tecnologias digitais na docência antes ou em decorrência da pandemia da COVID-19.

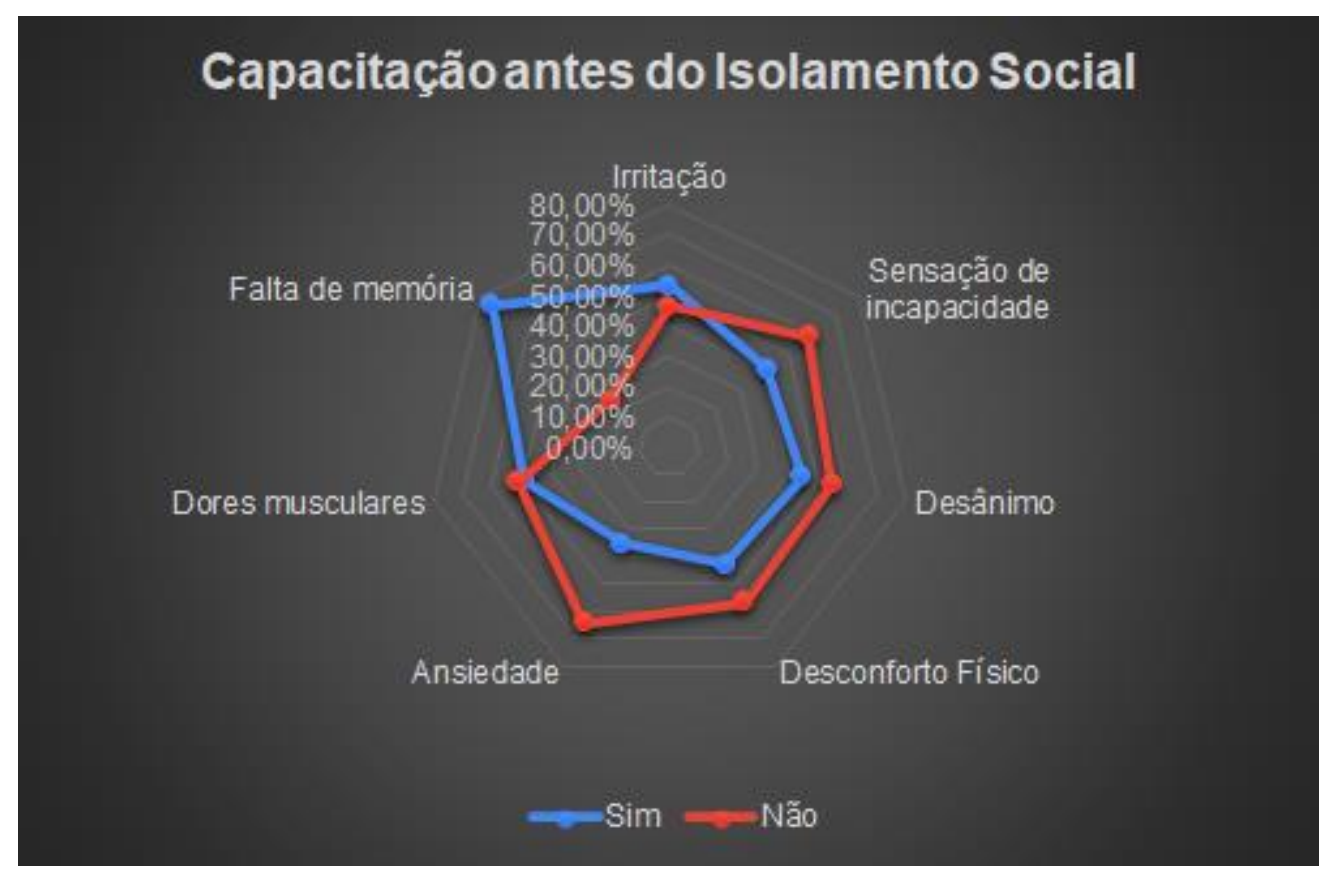

Figura 12. As sete dimensões de Estresse relacionadas à capacitação antes do Isolamento Social (Fonte: autores) 


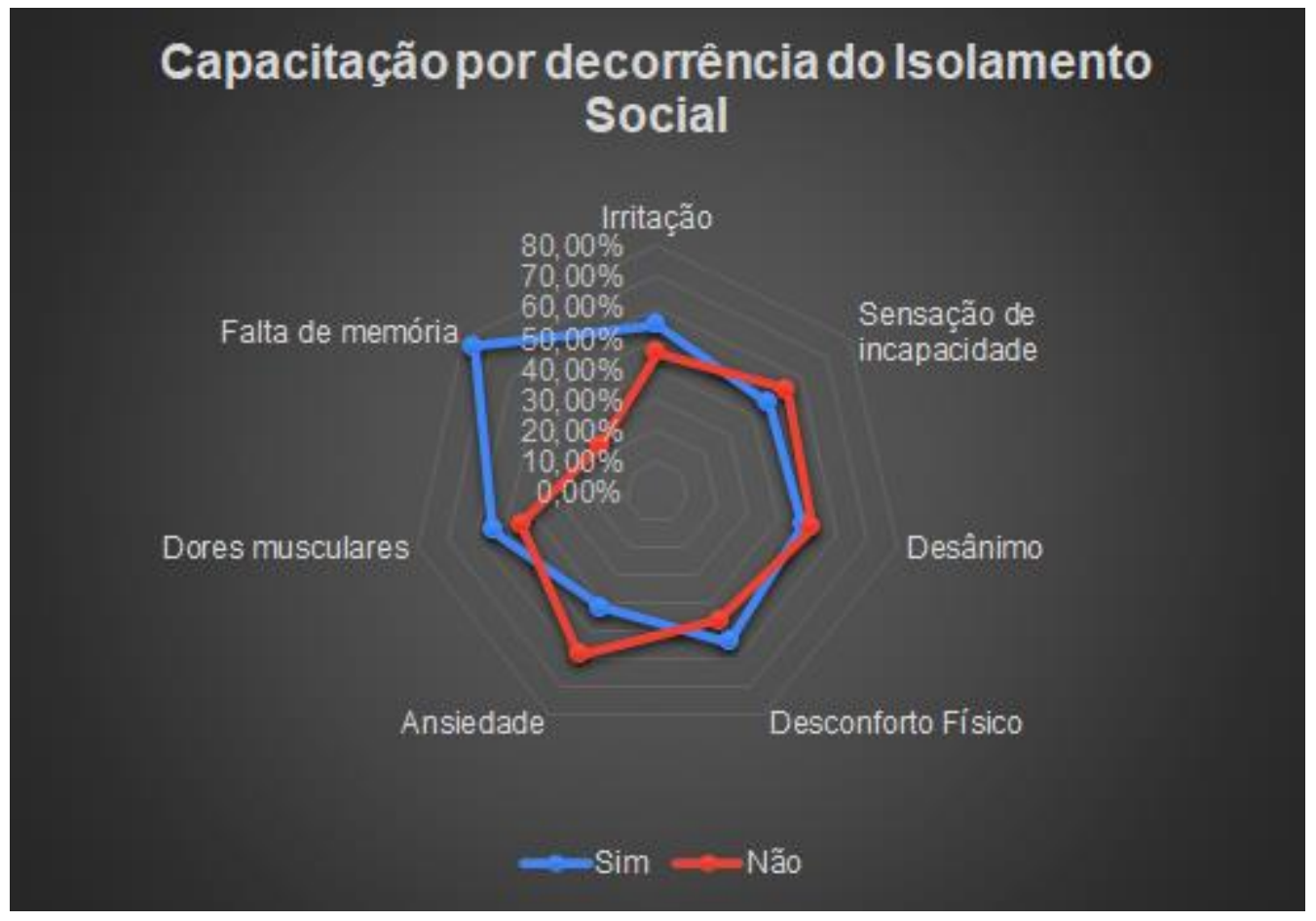

Figura 13. As sete dimensões de Estresse relacionadas à capacitação por decorrência do Isolamento Social (Fonte: autores)

Tabela 6: Relação entre Estresse e Capacitação

\begin{tabular}{|c|c|c|c|c|c|c|c|}
\hline \multicolumn{8}{|c|}{ Antes do Isolamento } \\
\hline & Irritação & $\begin{array}{l}\text { Sensação de } \\
\text { incapacidade }\end{array}$ & Desânimo & $\begin{array}{l}\text { Desconforto } \\
\text { Físico }\end{array}$ & Ansiedade & $\begin{array}{l}\text { Dores } \\
\text { musculares }\end{array}$ & $\begin{array}{l}\text { Falta de } \\
\text { memória }\end{array}$ \\
\hline Sim & $53,49 \%$ & $41,28 \%$ & $44,77 \%$ & $43,02 \%$ & $35,47 \%$ & $48,84 \%$ & $75,00 \%$ \\
\hline Não & $46,51 \%$ & $58,72 \%$ & $55,23 \%$ & $56,98 \%$ & $64,53 \%$ & $51,16 \%$ & $25,00 \%$ \\
\hline \multicolumn{8}{|c|}{ Por decorrência do Isolamento } \\
\hline Sim & $54,62 \%$ & $46,15 \%$ & $48,46 \%$ & $53,85 \%$ & $41,54 \%$ & $54,62 \%$ & $76,15 \%$ \\
\hline Não & $45,38 \%$ & $53,85 \%$ & $51,54 \%$ & $46,15 \%$ & $58,46 \%$ & $45,38 \%$ & $23,85 \%$ \\
\hline
\end{tabular}

\subsection{Limitações da Pesquisa}

O Instituto Nacional de Estudos e Pesquisas Educacionais Anísio Teixeira (INEP) reporta, em seu Censo da Educação Superior do ano de $2018^{4}$, um total de 384.474 docentes em exercício nas universidades brasileiras (173.868 na universidade pública e 210.606 em universidades privadas).

4

http://download.inep.gov.br/educacao_superior/censo_superior/documentos/2019/censo_da_educacao_superior_20 18-notas estatisticas.pdf 
Apesar de nosso estudo representar uma amostra de $0,10 \%$ deste universo (cujos números podem ter se atualizado de 2018 ao presente), destaca-se a emergência do período e a dificuldade de obtenção de dados.

Outra limitação do estudo, decorrente do processo de coleta de dados por conveniência, está no alto percentual de respondentes com atuação na área de Ciências Exatas e da Terra e Ciências da Saúde, refletindo o acesso mais direto à rede de contatos dos autores da pesquisa e seus respectivos contextos de atuação. Pela mesma razão, podemos apontar a limitação dos resultados decorrente do número expressivo de respondentes da região sudeste e sul do país, com destaque expressivo de respondentes do estado de São Paulo.

Apesar destas limitações, os dados levantados nesta pesquisa e os resultados de análise são de grande relevância para se compreender este cenário emergencial, contribuindo para o conhecimento de experiências gerado neste período singular no Brasil e no mundo.

\section{Conclusão}

A pandemia decorrente da COVID-19 trouxe mudanças profundas para toda a sociedade, seja no seu contexto social ou profissional. Vimos o uso das tecnologias de interação e comunicação sofrerem um grande aumento em praticamente todos os segmentos produtivos, permitindo que o trabalho agora fosse executado a partir dos lares de milhões de trabalhadores em todo mundo. $\mathrm{O}$ processo de ensino e aprendizagem também passou por fortes mudanças neste período, suportados pelas tecnologias digitais. O trabalho, as TICs e o estresse passaram a coabitar milhões de lares de professores no mundo todo.

Este artigo traz uma discussão sobre a relação entre os fatores de estresse em professores do ensino superior relacionados à adoção de práticas educacionais remotas durante a pandemia da COVID-19 no contexto brasileiro. O estudo buscou verificar a percepção dos professores de sinais e sintomas relacionados ao estresse associados ao período de distanciamento social.

Os dados coletados nesta pesquisa apontam que a percepção de estresse é real entre os docentes do ensino superior no Brasil que se mantiveram em atividade de ensino remoto durante o isolamento social decorrente da pandemia. O estudo deixou claro que há predominância de estresse nas professoras em relação aos professores; professores das áreas de Ciências Jurídicas e da Saúde parecem perceber mais o estresse; aqueles que se declararam com um nível de habilidade no uso de tecnologia mais baixo são os que mais sentiram as variáveis de estresse durante a pandemia.

A substituição de aulas presenciais por aulas mediadas por tecnologia teve seu prazo prorrogado, no Brasil, até dezembro de 2020 (pelo menos). Isto indica que os desafios superados pelos docentes para esta transição servirão de base para a continuidade destas atividades nos próximos meses. No entanto, muitos desafios ainda não superados permanecem em pauta que, combinados com o cenário de incerteza proporcionado pela pandemia, continuarão trazendo dúvidas e ansiedades, disparadoras de estresse, podendo levar à desmotivação, problemas físicos e alterações emocionais que comprometerão a qualidade de ensino aprendizagem e, no limite, e mais preocupante a saúde dos docentes.

Nossa pesquisa, embora limitada em escala, aponta para implicações importantes a serem consideradas tanto pela gestão das universidades, como pelas comunidades universitárias e, no limite, pelos próprios docentes, para evitar os quadros de estresse. É necessário um olhar flexível às demandas das professoras; um olhar transversal e intenso de acompanhamento do desenvolvimento de habilidades dos docentes no uso de tecnologia; uma compreensão global das realidades de atuação e formas de reagir ao uso de tecnologia por docentes de diferentes áreas de conhecimento; e a oferta de recursos tecnológicos e infraestrutura com suporte adequado aos 
docentes e discentes para suas atividades online. Os docentes precisam perceber apoio em suas limitações e dificuldades e a visão de planejamento de suas instituições.

Os dados levantados revelam que muitos fatores de estresse estão relacionados ao que Kuklinski e Cobo (2020) apontam como o primeiro e o segundo cenário de Ensino Remoto, que são fortemente dependentes de ações voluntárias do professorado, conforme discutido na seção 2.2. Possivelmente, em se mantendo algumas das experiências aprendidas durante a pandemia, em direção ao que os mesmos autores apontam como o terceiro e quarto cenários da adoção do Ensino Híbrido, os fatores de estresse possam vir a diminuir, já que tais cenários dependem de iniciativas mais institucionalizadas, não tão dependentes de ações individuais do professorado.

Este trabalho é uma contribuição para o corpo de conhecimento em construção acerca de nossas experiências durante a pandemia do novo coronavírus, momento singular na história, em particular registrando parte do cenário percebido pelos docentes do ensino superior no Brasil. Trabalhos futuros podem ser desenvolvidos no sentido de acompanhar estes resultados, realizando novos levantamentos para compreender a evolução da percepção de estresse entre os docentes. Além disso, este trabalho pode despertar novas iniciativas de projetos de pesquisa e ações direcionadas a diminuir os fatores estressores apresentados neste estudo.

\section{Agradecimentos}

Agradecemos a colaboração de todos os professores que, gentilmente, cederam parte de seu tempo para responder a este instrumento de coleta de dados sobre estresse no período de pandemia de Covid-19. O presente trabalho foi realizado com apoio da Coordenação de Aperfeiçoamento de Pessoal de Nível Superior - Brasil (CAPES) - Programa de Excelência - PROEX 1133/2019. Renata Araujo é Bolsista de Produtividade em Desenvolvimento Tecnológico e Extensão Inovadora do Conselho Nacional de Pesquisa (CNPQ) \#313210/2019-5.

\section{Referências}

Alves, M. D., \& Neto, J. C. P. (2019). Sofrimento psíquico no trabalho e estresse ocupacional em professores: causas e consequências. Revista Psicologia e Educação On-Line, 2(2), 40-46. Disponível em: http://psicologiaeeducacao.ubi.pt/Files/Other/Artigos\%200nLine/2019V2/6V2N2online2019.pdf [GS Search]

Aparicio, M., \& Bacao, F. (2013, July). E-learning concept trends. In Proceedings of the 2013 International Conference on Information Systems and Design of Communication (pp. 81-86). doi: 10.1145/2503859.2503872 [GS Search]

Araujo, R. M., \& Pimentel, M. (2020). \#Fique em Casa, mas se mantenha ensinando-aprendendo: algumas questões educacionais em tempos de pandemia. SBC Horizontes. ISSN: 2175-9235. Disponível em: http://horizontes.sbc.org.br/index.php/2020/03/30/fiqueemcasa/

Araújo, F. J. O., de Lima, L. S. A., Cidade, P. I. M., Nobre, C. B., \& Neto, M. L. R. (2020). Impact of Sars-Cov-2 And its reverberation in global higher education and mental health. Psychiatry Research, 112977. doi: 10.1016/j.psychres.2020.112977 [GS Search]

Baião, L. D. P. M., \& Cunha, R. G. (2013). Doenças e/ou disfunções ocupacionais no meio docente: uma revisão de literatura. Formação@ Docente, 5(1), 6-21. doi: 10.15601/2237$\underline{0587 / f d . v 5 n 1 p 6-21}$ [GS Search] 
Brasil. Ministério da Educação. (2018). O que é educação a distância? Disponível em: http://portal.mec.gov.br/escola-de-gestores-da-educacao-basica/355-perguntas-frequentes911936531/educacao-a-distancia-1651636927/12823-o-que-e-educacao-a-distancia.

Brasil. Ministério da Educação. (2020). PORTARIA N 343, DE 17 DE MARÇO DE 2020. Disponível

em: https://legislacao.presidencia.gov.br/atos/?tipo=PRT\&numero=343\&ano=2020\&ato=6f5UT VE5EMZpWT599

Brasil. Ministério da Educação. (2020a). PORTARIA N 473, DE 12 DE MAIO DE 2020. Disponível em: http://www.in.gov.br/en/web/dou/-/portaria-n-473-de-12-de-maio-de-2020$\underline{256531507}$

Brasil. Ministério da Educação. (2020b). PORTARIA Nº 544, DE 16 DE JUNHO DE 2020. Disponível em: https://covid.inteligov.com.br/publicacoes/42699-portaria-n-544-de-16-dejunho-de-2020

Calais, S. L., Andrade, L. M. B. D., \& Lipp, M. E. N. (2003). Diferenças de sexo e escolaridade na manifestação de stress em adultos jovens. Psicologia: Reflexão e crítica, 16(2), 257-263. doi: 10.1590/S0102-79722003000200005 [GS Search]

Carlotto, M. S., \& Palazzo, L. D. S. (2006). Síndrome de burnout e fatores associados: um estudo epidemiológico com professores. Cadernos de Saúde Pública, 22, 1017-1026. Disponível em: https://www.scielosp.org/article/csp/2006.v22n5/1017-1026/pt/ [GS Search]

Cordeiro, J. A., Guillen, G., Gala, L., Lupiani, M., Benitez, G., \& Gómez, A. (2003). Prevalencia del Síndrome de Burnout en los maestros. Resultados de una investigación preliminar. Psicologia. com, 7(1), 1-6. Disponível em: https://psiquiatria.com/estres-62/prevalencia-delsindrome-de-burnout-en-los-maestros-resultados-de-una-investigacion-preliminar/

Costa, C. J. (2007). Modelos de educação superior a distância e implementação da Universidade Aberta do Brasil. Revista Brasileira de Informática na Educação, 15(2). Disponível em: https://www.br-ie.org/pub/index.php/rbie/article/view/63 [GS Search]

Dotta, S., Aguiar, P. H. L., de Oliveira, C. A., \& da Cunha Jorge, É. F. (2014). A mediação em aulas virtuais síncronas via webconferência. Revista Brasileira de Informática na Educação, 22(01), 56. doi: 10.5753/rbie.2014.22.01.56 [GS Search]

Faria, D. D. P., \& Gallo-Penna, E. C. (2009). Dimensões do estresse na carreira docente de professores do ensino fundamental. FAZU em Revista, (06). Disponível em: https://www.fazu.br/ojs/index.php/fazuemrevista/article/viewFile/30/24

Fogaça, M. D. C., Carvalho, W. B. D., Cítero, V. D. A., \& Nogueira-Martins, L. A. (2010). Preliminary study about occupational stress of physicians and nurses in pediatric and neonatal intensive care units: the balance between effort and reward. Revista latino-americana de enfermagem, 18(1), 67-72. doi: 10.1590/S0104-11692010000100011 [GS Search]

Fundação Carlos Chagas. (2020). Educação escolar em tempos de pandemia na visão de professoras/es da Educação Básica. Disponível em: https://www.fcc.org.br/fcc/fccnoticia/fcc-divulga-resultados-iniciais-de-pesquisa

Genuíno, S. L. V. P., da Silva Gomes, M., \& de Moraes, E. M. (2009). O Estresse ocupacional e a Síndrome de Burnout no ambiente de trabalho: suas influências no comportamento dos professores da rede privada do Ensino Médio de João Pessoa. Anagrama, 3(2), 1-9. Disponível em: https://www.revistas.usp.br/anagrama/article/view/35426 [GS Search]

Gomes, J. H., \& Caetano, J. C. R. (2014). Educação a distância, democracia e sustentabilidade. Jequié/Lisboa: Associação Brasileira de Educação a Distância. Disponível em: 
http://www.abed.org.br/hotsite/20-ciaed/pt/anais/pdf/172.pdf

Goulart Junior, E., \& Lipp, M. E. N. (2008). Estresse entre professoras do ensino fundamental de escolas públicas estaduais. Psicologia em estudo, 13(4), 847-857. doi: 10.1590/S141373722008000400023 [GS Search]

Guglielmi, R. S., \& Tatrow, K. (1998). Occupational stress, burnout, and health in teachers: A methodological and theoretical analysis. Review of educational research, 68(1), 61-99. doi: $\underline{10.3102 / 00346543068001061}$ [GS Search]

Hindle, T. (1998). Como reduzir o estresse. Dorling kindersley Limited.

Hodges, C., Moore, S., Lockee, B., Trust, T., \& Bond, A. (2020). The difference between emergency remote teaching and online learning. Educause Review, 27. Disponível em: https://medicine.hofstra.edu/pdf/faculty/facdev/facdev-article.pdf [GS Search]

Huang, Y., \& Zhao, N. (2020). Chinese mental health burden during the COVID-19 pandemic. Asian Journal of Psychiatry, 51, 102052. doi: 10.1016/j.ajp.2020.102052 [GS Search]

Kuklinski, H.P., \& Cobo, C. (2020). Expandir la universidad más allá de la enseñanza remota de emergencia - Ideas hacia un modelo híbrido post-pandemia. Outliers School. Barcelona. Disponível em: http://outliersschool.net/project/universidadpostpandemia/

Lazzarotto, L. L., de Paiva Oliveira, A., Braga, J. L., \& dos Passos, F. J. V. (2011). A educação em ambientes virtuais: proposição de recursos computacionais para aumentar a eficiência do processo ensino-aprendizado. Revista Brasileira de Informática na Educação, 19(02), 42. doi: $10.5753 /$ rbie.2011.19.02.42 [GS Search]

Lederman, D. (2020). Will shift to remote teaching be boon or bane for online learning. Inside Higher Ed. Disponível em: https://www.insidehighered.com/digitallearning/article/2020/03/18/most-teaching-going-remote-will-help-or-hurt-online-learning

Leite, A. F., \& Nogueira, J. A. D. (2017). Fatores condicionantes de saúde relacionados ao trabalho de professores universitários da área da saúde: uma revisão integrativa. Revista Brasileira de Saúde Ocupacional, 42. doi: 10.1590/2317-6369000010116 [GS Search]

Leiter, M. P., \& Maslach, C. (2017). Burnout and engagement: Contributions to a new vision. Burnout Research, 5, 55-57. doi: 10.1016/j.burn.2017.04.003 [GS Search]

Lipp, M. N (Org). (2002). O Stress do Professor. Campinas (SP): Papirus.

Luca, J. (2006, January). Using blended learning to enhance teaching and learning. In Proceedings of the 8th Australasian Conference on Computing Education-Volume 52 (pp. 3-4). Disponível em: https://dl.acm.org/doi/pdf/10.5555/1151869.1151870 [GS Search]

Martins, M. D. G. T. (2007). Sintomas de stress em professores brasileiros. Revista Lusófona de Educação, (10), 109-128. Disponível em: http://www.scielo.mec.pt/scielo.php?pid=S1645$72502007000200009 \&$ script=sci_arttext\&tlng=en [GS Search]

Maslach, C., \& Jackson, S. E. (1981). The measurement of experienced burnout. Journal of organizational behavior, 2(2), 99-113. doi: 10.1002/job.4030020205 [GS Search]

Mesquita, A. A., Gomes, D. S., Lobato, J. L., Gondim, L., \& de Souza, S. B. (2013). Estresse e síndrome de burnout em professores: Prevalência e causas. Psicologia Argumento, 31(75). doi: 10.7213/psicol.argum.31.075.DS05 [GS Search]

Mezzaroba, O., Feitosa, R. J. R, Silveira, V.O \& Séllos-Knoerr, V. C. (2014) Direito e Novas Tecnologias. Curitiba: Clássica Editora.

Miranda, L. C. S., Pereira, C. A., \& Passos, J. P. (2009). O estresse nos docentes de enfermagem de uma universidade pública. Revista de Pesquisa: Cuidado é Fundamental Online, 1(2). 
Disponível em: http://www.seer.unirio.br/index.php/cuidadofundamental/article/view/410 [GS Search]

Moore, M. G. (1972). Learner autonomy: The second dimension of independent learning. Convergence, $5(2), \quad 76 . \quad$ Disponível em: https://search.proquest.com/openview/026768752863637ca2c2f4efd6eb0140/1?pqorigsite $=$ gscholar \&cbl=2030445 [GS Search]

Moore, M. G., \& Diehl, W. C. (2019). Handbook of Distance Education. Fourth Edition. New York: Routledge.

Oliveira, E. R. A. D., Garcia, Á. L., Gomes, M. J., Bittar, T. O., \& Pereira, A. C. (2012). Gênero e qualidade de vida percebida: estudo com professores da área de saúde. Ciência \& Saúde Coletiva, 17, 741-747. Disponível em: https://www.scielosp.org/article/csc/2012.v17n3/741747/ [GS Search]

Odriozola-González, P., Planchuelo-Gómez, Á., Irurtia, M. J., \& de Luis-García, R. (2020). Psychological effects of the COVID-19 outbreak and lockdown among students and workers of a Spanish university. Psychiatry Research, 113108. doi: 10.1016/j.psychres.2020.113108 [GS Search]

Pather, N., Blyth, P., Chapman, J. A., Dayal, M. R., Flack, N. A., Fogg, Q. A., Green, R. A., Hulme, A. K., Johnson, I. P., Meyer, A. J., Morley, J. W., Shortland, P. J., Mirjana, G., Valter, K., Webb, A. L., Woodley, S. J., \& Lazarus, M. D. (2020). Forced Disruption of Anatomy Education in Australia and New Zealand: An Acute Response to the Covid-19 Pandemic. Anatomical sciences education, 13(3), 284-300. doi: 10.1002/ase.1968 [GS Search]

Peters, O. (2004). A educação a distância em transição. Editora UNISINOS, São Leopoldo.

Pistone, M. (2015). Law schools and technology: where we are and where we are heading. Journal of Legal Education, 64(4), 586-604. [GS Search]

Plessis, M. (2019). Coping with occupational stress in an open distance learning university in South Africa. Journal of Psychology in Africa, 29(6), 570-575. doi: 10.1080/14330237.2019.1689466 [GS Search]

Poalses, J., \& Bezuidenhout, A. (2018). Mental health in higher education: A comparative stress risk assessment at an open distance learning university in South Africa. International Review of Research in Open and Distributed Learning, 19(2). doi: 10.19173/irrodl.v19i2.3391 [GS Search]

Prado, C. E. P. (2016). Estresse ocupacional: causas e consequências. Rev Bras Med Trab. 14(3):285-9. doi: 10.5327/Z1679-443520163515 [GS Search]

Sá, S. C. D. A., Silva, R. M. D., Kimura, C. A., Pinheiro, G. Q., Guido, L. D. A., \& Moraes Filho, I. M. (2018). Estresse em docentes universitários da área de saúde de uma faculdade privada do entorno do Distrito Federal. Revista de Divulgação Científica Sena Aires, 7(3), 200-207. Disponível em: http://revistafacesa.senaaires.com.br/index.php/revisa/article/view/321 [GS Search]

Sadir, M. A., Bignotto, M. M., \& Lipp, M. E. N. (2010). Stress e qualidade de vida: influência de algumas variáveis pessoais. Paideia, 20(45), 73-81. Disponível em: https://www.redalyc.org/pdf/3054/305423775010.pdf [GS Search]

Sahu, P. (2020). Closure of universities due to Coronavirus Disease 2019 (COVID-19): impact on education and mental health of students and academic staff. Cureus, 12(4). doi: $\underline{10.7759 / \text { cureus.7541 [GS Search] }}$ 
Sarmento, T. S., Gomes, A. S., \& Moreira, F. (2018, October). Classroom adaptations for blended learning practices. In Proceedings of the Sixth International Conference on Technological Ecosystems for Enhancing Multiculturality (pp. 723-728). doi: 10.1145/3284179.3284296 [GS Search]

Thomson, D. I. (2009). Law school 2.0: Legal education for a digital age. LexisNexis.

Weber, L. N. D., Leite, C. R., Stasiak, G. R., da Silva Santos, C. A., \& Forteski, R. (2015). O estresse no trabalho do professor. Imagens da educação, 5(3), 40-52. doi: 10.4025/imagenseduc.v5i3.25789 [GS Search]

Weller, M. (2020). 25 Years of Ed Tech. Au Press. Edmonton. [GS Search] 